University of Wollongong

Research Online

Faculty of Science, Medicine and Health -

Papers: part A

Faculty of Science, Medicine and Health

$1-1-2011$

\title{
Luminescence dating of K-feldspar from sediments: a protocol without anomalous fading correction
}

Bo Li

University of Hong Kong, bli@uow.edu.au

Sheng-Hua Li

University of Hong Kong

Follow this and additional works at: https://ro.uow.edu.au/smhpapers

Part of the Medicine and Health Sciences Commons, and the Social and Behavioral Sciences

Commons

\section{Recommended Citation}

$\mathrm{Li}, \mathrm{Bo}$ and Li, Sheng-Hua, "Luminescence dating of K-feldspar from sediments: a protocol without anomalous fading correction" (2011). Faculty of Science, Medicine and Health - Papers: part A. 263.

https://ro.uow.edu.au/smhpapers/263

Research Online is the open access institutional repository for the University of Wollongong. For further information contact the UOW Library: research-pubs@uow.edu.au 


\title{
Luminescence dating of K-feldspar from sediments: a protocol without anomalous fading correction
}

\author{
Abstract \\ A protocol for optical dating of potassium-rich feldspar (K-feldspar) is proposed. It utilizes the infrared \\ stimulated luminescence (IRSL) signal measured by progressively increasing the stimulation temperature \\ from 50 to $250{ }^{\circ} \mathrm{C}$ in step of $50^{\circ} \mathrm{C}$, so-called multi-elevated-temperature post-IR IRSL (MET-pIRIR) \\ measurements. Negligible anomalous fading was observed for the MET-pIRIR signals obtained at 200 and \\ $250^{\circ} \mathrm{C}$. This was supported by equivalent dose (De) measurements using the IRSL and MET-pIRIR signals. \\ The De values increase progressively from $50^{\circ} \mathrm{C}$ to $200^{\circ} \mathrm{C}$, but similar De values were obtained for the \\ MET-pIRIR signal at 200 and $250^{\circ} \mathrm{C}$. Measurement of modern samples and bleached samples indicates \\ that the MET-pIRIR signals have small residual doses less than $5 \mathrm{~Gy}$ equivalent to about $1-2 \mathrm{ka}$. We have \\ tested the protocol using various sedimentary samples with different ages from different regions of \\ China. The MET-pIR IRSL ages obtained at 200 and $250^{\circ} \mathrm{C}$ are consistent with independent and/or quartz \\ OSL ages.

\section{Keywords} \\ luminescence, anomalous, without, protocol, correction, sediments, fading, feldspar, k, dating, CAS

\section{Disciplines} \\ Medicine and Health Sciences | Social and Behavioral Sciences

\section{Publication Details} \\ Li, B. \& Li, S. (2011). Luminescence dating of K-feldspar from sediments: a protocol without anomalous \\ fading correction. Quaternary Geochronology, 6 (5), 468-479.
}




\title{
Luminescence dating of $\mathrm{K}$-feldspar from sediments: A protocol without anomalous fading correction
}

\author{
Bo Li* and Sheng-Hua Li
}

Department of earth Sciences, The University of Hong Kong, Pokfulam Road, Hong Kong, China

*Corresponding author. Email: boli@hku.hk

\begin{abstract}
A protocol for optical dating of potassium-rich feldspar ( $\mathrm{K}$-feldspar) is proposed. It utilizes the infrared stimulated luminescence (IRSL) signal measured by progressively increasing the stimulation temperature from 50 to $250^{\circ} \mathrm{C}$ in step of $50^{\circ} \mathrm{C}$, so called multi-elevated-temperature postIR IRSL (MET-pIRIR) measurements. Negligible anomalous fading was observed for the METpIRIR signals obtained at 200 and $250^{\circ} \mathrm{C}$. This was supported by equivalent dose $\left(\mathrm{D}_{\mathrm{e}}\right)$ measurements using the IRSL and MET-pIRIR signals. The $\mathrm{D}_{\mathrm{e}}$ values increase progressively from $50^{\circ} \mathrm{C}$ to $200^{\circ} \mathrm{C}$, but similar $D_{e}$ values were obtained for the MET-pIRIR signal at 200 and $250^{\circ} \mathrm{C}$. Measurement of modern samples and bleached samples indicates that the MET-pIRIR signals have small residual doses less than 5 Gy equivalent to about 1-2 ka. We have tested the protocol using various sedimentary samples with different ages from different regions of China. The MET-pIR IRSL ages obtained at 200 and $250{ }^{\circ} \mathrm{C}$ are consistent with independent and/or quartz OSL ages.
\end{abstract}

Keywords: feldspar, luminescence, IRSL, post-IR, anomalous fading, sediment. 


\section{Introduction}

Dating of sedimentary deposits can be achieved using optically stimulated luminescence (OSL) signal from quartz and feldspar grains from sediments (Aitken, 1998). The luminescence signals of quartz or feldspar are used to measure the dose received by the grains in their sedimentary environment since deposition. The age is obtained by dividing the absorbed dose or equivalent dose $\left(D_{e}\right)$ (in Gy) by the dose rate (in Gy/ka) which is derived from the decay of radionuclides in the sediments, and a contribution from cosmic rays (Aitken, 1985). In the last decade, with the development of single-aliquot regenerative-dose (SAR) protocol (Murray and Wintle, 2000), quartz OSL dating has been widely applied to dating Quaternary sediments (Murray and Olley, 2002; Wintle and Murray, 2006; Wintle, 2008). However, dating of old deposits is limited by the saturation of the quartz OSL signal with increasing dose (Wintle and Murray, 2006).

The infrared stimulated luminescence (IRSL) from sedimentary feldspar has been used for optical dating of sediment for the last two decades since the first report of optical stimulation spectra of feldspar by Hütt et al. (1988). The IRSL signal from feldspars is particularly useful for dating as it has several advantages over the OSL signal of quartz. Firstly, the IRSL signal from sand-sized Kfeldspar grains saturate at higher doses than the quartz OSL signal; thus it has the potential for extending the datable range for sedimentary deposits. Secondly, when using appropriate filters to reject the stimulation light in each case, the IRSL signals are often much brighter than the quartz OSL signal; this enables high precision luminescence measurements to be made. This leads to a high reproducibility for natural dose measurements ( $\mathrm{Li}$ et al., 2007b). The high contribution of the internal dose rate from ${ }^{40} \mathrm{~K}$ and ${ }^{87} \mathrm{Rb}$ will also result in higher equivalent doses for young samples; thus it has a greater potential for the younger age limit (Li et al., 2007b).

Despite of various advantages over quartz OSL dating, the application of IRSL dating of Kfeldspars has long been limited due to anomalous fading, an athermal process of decay of luminescence signals during storage at ambient temperature after irradiation, as first noted for the 
thermoluminescence (TL) signals from feldspars by Wintle (1973). Later, the IRSL signals have also been shown to anomalously decrease with storage at room temperature at which the signals are supposed to be thermally stable (Spooner, 1992, 1994; Huntley and Lamothe, 2001; Huntley and Lian, 2006). The anomalous fading of the luminescence signal has been suggested as the main reason for the age shortfall in IRSL dating of feldspar (Lamothe and Auclair, 1999; Huntley and Lamothe, 2001; Huntley and Lian, 2006; Li et al., 2007a).

Given the great potential of extending the age range of luminescence dating using feldspar, attempts have been made to correct for or to avoid the anomalous fading effect (Sanderson and Clark, 1994; Lamothe and Auclair, 1999; Huntley and Lamothe, 2001; Zhao and Li, 2002; Lamothe et al., 2003; Tsukamoto et al., 2006; Li et al., 2008). Huntley and Lamothe (2001) proposed a method to correct for the anomalous fading using K-feldspar, based on the measurement of the fading rate ( $\mathrm{g}$ value) in terms of percentage loss per decade (Aitken, 1985). However, this method can only be applied to young samples with linear dose response curves. For older samples, such method becomes unreliable as a result of dose-dependent changes in anomalous fading rate (Kars et al., 2008; Li and Li, 2008).

Recent studies suggested that the initial part of the IRSL signal has a higher anomalous fading rate when compared to the later part (Thomsen et al., 2008; Li, 2010). This observation has led to the development of post-IR IRSL (pIRIR) dating methods, in which an IRSL bleaching at low temperature $\left(\sim 50^{\circ} \mathrm{C}\right)$ is applied before a high temperature $\left(>200^{\circ} \mathrm{C}\right)$ IRSL measurement to reduce the fading rate of feldspar (Thomsen et al., 2008; 2010; Buylaert et al., 2009; Thiel et al., 2010). However, detectable anomalous fading is still present in the pIRIR $\left(225^{\circ} \mathrm{C}\right)$ signals (Buylaert et al., 2009) and fading correction has not been avoided although the magnitude of age correction is reduced. More recently, Thiel et al. (2010) and Thomsen et al. (2010) both show evidence for the natural pIRIR $\left(290^{\circ} \mathrm{C}\right)$ signal being in saturation on a laboratory dose response curve, indicating that the signals may 
be stable, but they both report non-zero laboratory fading rates $(1.1 \pm 0.3 \% /$ decade and $1.3 \pm$ $0.4 \% /$ decade, respectively).

Given the ambiguity of the one-step pIRIR signal stability and the strong model dependence of the fading correction procedure, especially for old samples ( $\mathrm{Li}$ and $\mathrm{Li}, 2008$ ), searching for nonfading signal from feldspar is necessary. In this paper, we propose a dating method for K-feldspars that utilises the IRSL and multi-elevated-temperatures post-IR IRSL ((MET-pIRIR) signals. We show that using this protocol yields reliable ages and avoids anomalous fading corrections.

\section{Samples and analytical facilities}

Eleven aeolian sedimentary samples from three different deserts from Northern China, namely the Mu Us, Hulun Buir and Hunshandake, and two loess samples from the Chinese Loess Plateau were used in this study. Fig. 1 shows the location of the sampling sites. Table 1 shows a list of all samples used in this study. Samples WG1, WG2 and WG3 from Wan Gong (WG) and HLD3 from He Er Hong De (HLD) were taken from the Hulun Buir Desert. Samples SGDL10, SGDL11 and SY3 were taken from San Gen Da Lai (SGDL) and San Yi (SY) sites from the Hunshandake Desert (Li et al., 2002; Li and Sun, 2006). These samples have quartz OSL ages in the range of 0-13 ka. Sample FJGW1 was taken from the Fanjiagouwan site on the bank of the Sala Us River at the south edge of the $\mathrm{Mu}$ Us Desert. An IRSL Isochron age of $54 \pm 7 \mathrm{ka}$ was derived for this sample, a similar age of 55.7 \pm 1.0 ka was also obtained based on quartz OSL measurements (Fan et al., 2011). Samples Sm3, Sm5, Sm0404 and Sm8 were taken from the Shimao section in the transition zone between the Mu Us Desert and the Loess plateau ( $\mathrm{Li}$ et al. submitted). The isochron ages obtained using the K-feldspar grains in different grain sizes for samples Sm3, Sm0404 and Sm5 were 41 $\pm 6,92 \pm 20$ and $121 \pm 26 \mathrm{ka}$, respectively, which are consistent with the model ages based on stratigraphical correlation (Sun et al., 1999; Li et al., 2008). The age of Sm8 ( 0.5 Ma) was estimated by correlation between stratigraphy and marine oxygen isotopic stages (OIS 12) (Li and Li, 2008; Li et al., submitted). Previous study on the equivalent dose of the samples from the section suggested that the IRSL signal for sample Sm8 
has reached an equilibrium state, i.e. the IRSL traps were in equilibrium between electron filling and escaping (or fading) ( $\mathrm{Li}$ and $\mathrm{Li}, 2008$; Li et al., submitted). This is so-called "field saturation" (Lamothe et al., 2003; Huntley and Lian, 2006). Two loess samples LC-019 and LC-093 were from the Luochuan section of the Chinese Loess Plateau with sampling depths of 1.9 and $9.3 \mathrm{~m}$, respectively. The sample LC-019 is located at the upper part of the $\mathrm{L}_{1}$ bed. The age of LC-019 is expected to be $20 \pm 3 \mathrm{ka}$, based on that the quartz OSL ages for the samples at depth of 1.8 and $2.0 \mathrm{~m}$ are $16.1 \pm 0.7$ and $23.2 \pm 1.1 \mathrm{ka}$ (Lu et al., 2007), respectively. The sample LC-093 is located at the transition layer between the $L_{1}$ and $S_{1}$ beds, which is expected to have an age of $70 \pm 5$ ka according to the quartz OSL ages in the similar depth (Lai, 2010; Lu et al., 2007) and the grain-size model age proposed by Porter and An (1995).

Coarse K-feldspar grains (125-150 or 150-212 $\mu \mathrm{m}$ from sand samples and $63-90 \mu \mathrm{m}$ from loess samples) were extracted using standard preparation methods ( $\mathrm{Li}$ et al., 2008). The K-feldspar grains were etched using $10 \% \mathrm{HF}$ for 40 minutes to remove the alpha irradiated surface layer of the grains. The K-feldspar IRSL measurements were made on an automated Risø TL-DA-20 reader equipped with IR diodes $(870 \Delta 40 \mathrm{~nm})$ for stimulation (Bøtter-Jensen et al., 2003a). The IR power delivered to the sample position was $90 \%$ of the maximum power $\left(\sim 140 \mathrm{~mW} / \mathrm{cm}^{2}\right)$. The IRSL signals were detected using a photomultiplier tube with the IRSL passing through a filter pack containing Schott BG-39 and Corning 7-59 filters, which allows for a transmission peaked in blue (320-480 nm).

Quartz grains of 125-150 $\mu \mathrm{m}$ diameter were also extracted for the sand samples; these were etched with $40 \% \mathrm{HF}$ for one hour to eliminate feldspar. Quartz OSL signals were measured on a Risø TL-DA-15 reader equipped with blue LEDs for stimulation. The OSL signal was measured at $125^{\circ} \mathrm{C}$ for $100 \mathrm{~s}$ and was detected using a photomultiplier tube with the OSL signal passing through $7.5 \mathrm{~mm}$ thick U-340 filters. The quartz $\mathrm{D}_{\mathrm{e}}$ values were determined using a single-aliquot regenerative-dose (SAR) protocol (Murray and Wintle, 2000) with preheat at $260^{\circ} \mathrm{C}$ for $10 \mathrm{~s}$ and cut-heat to $220^{\circ} \mathrm{C}$ for regenerative doses and test doses, respectively. 
Aliquots containing several hundred grains were prepared by mounting the grains in a monolayer on a $9.8 \mathrm{~mm}$ diameter aluminum disc with "Silkospay" silicone oil. Irradiations were carried out within the readers using a ${ }^{90} \mathrm{Sr} /{ }^{90} \mathrm{Y}$ beta source. In the sunlight bleaching experiments (section 4.2), an ORIEL sunlight simulator was used. It has a similar spectrum as sunlight.

The environmental (or external) dose rates were measured using several techniques. The contribution from $\mathrm{U}$ and Th decay chains were determined using the Thick-source alpha counting (TSAC) technique (Aitken, 1985). The K content was measured using X-ray fluorescence (XRF). The water content was calculated from the sample weights before and after drying. The contribution from cosmic ray was calculated from the burial depth and the latitude and altitude of the samples (Prescott and Hutton, 1994). The internal dose rate for K-feldspar used in age calculation was estimated by assuming $\mathrm{K}=13 \pm 1 \%$ and $\mathrm{Rb}=400 \pm 100 \mathrm{ppm}$ (Li et al. 2008; Huntley and Baril, 1997; Zhao and $\mathrm{Li}$, 2005; Huntley and Hancock, 2001). A summary of the dosimetry data for all samples is listed in Table 1.

\section{Description of the protocol}

Recent studies have suggested that tunneling between spatially close donor-acceptor pairs from IR-excited state plays an important role in the production of the IRSL from K-feldspar (Poolton et al., 2002a,b; Thomsen et al. 2008; Li, 2010; Jain and Ankjærgaard, 2011). Based on the study of the thermal activation energy of IRSL signal from K-feldspar, Li (2010) suggested that the initial part of the IRSL signal measured at $50{ }^{\circ} \mathrm{C}$ is mainly a result from tunneling recombination, while thermal assisted recombination become important in the later part. Thomsen et al (2008) observed that there is a lower fading rate for the later part of IRSL signal compared with that from the initial part and explained it as a result of increasing mean distance to recombination centres. These studies indicate that those spatially close trapped electron-hole pairs will preferentially recombined under IR stimulation. Therefore, it was expected that a non-fading signal from feldspar may be accessible by using a post-IR IRSL procedure. This has led to the development of the post-IR IRSL dating method, 
in which an IRSL bleaching at low temperature $\left(\sim 50^{\circ} \mathrm{C}\right)$ is applied before a high temperature $\left(>200^{\circ} \mathrm{C}\right)$ IRSL measurement to reduce the fading rate of feldspar (Thomsen et al., 2008; Buylaert et al., 2009; Thiel et al., 2010). However, Li (2010) observed similar thermal activation energies for the natural IRSL and regenerative IRSL and argued that the term 'distant electron-hole pairs' is not exactly the same for the ground state and the IR-excited state. This indicated that the distant electron-hole pairs at the ground state might not be necessarily all 'distant' at excited state, and vice versa. It is therefore expected that a short IR bleaching in laboratory (up to several hundred seconds) at $50{ }^{\circ} \mathrm{C}$ cannot completely remove all of the charges in easy-to-fade traps and, as a result, the subsequent hightemperature post-IR IR stimulation may have contribution from the remaining charges in easy-to-fade traps. It is therefore necessary to explore appropriate experimental procedure to separate the signals of relating to easy-to-fade traps from those of non-fading traps.

In the study of the relationship between IRSL decay curve shape and anomalous fading, $\mathrm{Li}$ (2010) showed evidences for that post-IR at elevated temperatures could access those easy-to-fade electron-hole pairs that are not accessible by low temperature IRSL, indicating that a higher stimulation temperature used in the first IR stimulation will remove more easy-to-fade signals than stimulation at low temperature does. However, since thermal assisted recombination is also an important process in IRSL production (Li, 2010; Jain and Ankjærgaard, 2011), it is expected that IR stimulation at elevated temperature will preferentially remove those distant electron-hole pairs compared to the stimulation at low temperature, which reduce the effectiveness in removing easy-tofading signals using high-temperature IRSL. Therefore, it is hypothesized that a progressive increase of stimulation temperature will progressively remove the easy-to-fade electron-hole pairs, in a better way than a single IR stimulation at low temperature or high temperature does. Hence, we proposed a multiple stimulation procedure at different stimulation temperatures.

The basic structure of this protocol is similar to the single-aliquot-regnerative (SAR) dose protocol (Murray and Wintle, 2000; Li et al., 2008), but a different IRSL measurment procedure was 
adopted. A detailed procedure of the protocol was shown in Table 2. In this protocol, a preheat temperature of $300^{\circ} \mathrm{C}$ (step 2 and 9) for $10 \mathrm{~s}$ was applied after both regenerative and test doses to avoid significant influence from TL to the $250{ }^{\circ} \mathrm{C}$ IRSL measurement (step 7 and 14). After the preheat, the IRSL and MET-pIRIR signals of both regenerative and test doses are measured by increasing the stimulation temperature in steps of $50^{\circ} \mathrm{C}$, i.e. $50,100,150,200$ and $250^{\circ} \mathrm{C}$ (Table 2 ). At the end of the IRSL measurements for each test dose, a 'hot' IR bleach at $320^{\circ} \mathrm{C}$ for $100 \mathrm{~s}$ (step 15) is conducted to ensure a low residual of IRSL signal for the next cycle.

It is to be noted that this protocol is different from the one-step post-IR IRSL (pIRIR) procedure proposed by Thomsen et al (2008) and Buylaert et al (2009), in which two IRSL measurements were applied after each irradiation and preheat, i.e. a high-temperature IRSL was measured immediately after a low-temperature IRSL measurment at $50{ }^{\circ} \mathrm{C}$. To distinguish it from previous pIRIR methods, we have termed it as multi-elevated-temperatures post-IR IRSL (METpIRIR) method. Using this protocol, five IRSL curves are measured at five different stimulation temperatures, which means that five equivalent doses could be obtained accordingly, i.e. each equivalent dose is calculated based on sensitivity-corrected IRSL signals at different stimulation temperatures. The IRSL signal observed at temperature $t^{\circ} \mathrm{C}\left(\mathrm{L}_{\mathrm{x}(\mathrm{t})}\right)$ is corrected for sensitivity change using the respective test dose IRSL signal measured at the same temperature $\left(\mathrm{T}_{\mathrm{x}(\mathrm{t})}\right)\left(\mathrm{e} \cdot \mathrm{g} \cdot \mathrm{L}_{\mathrm{x}(50)} / \mathrm{T}_{\mathrm{x}(50)}\right.$, $\mathrm{L}_{\mathrm{x}(100)} / \mathrm{T}_{\mathrm{x}(100)}, \mathrm{L}_{\mathrm{x}(150)} / \mathrm{T}_{\mathrm{x}(150)}, \mathrm{L}_{\mathrm{x}(200)} / \mathrm{T}_{\mathrm{x}(200)}$ and $\mathrm{L}_{\mathrm{x}(250)} / \mathrm{T}_{\mathrm{x}(250))}$. One advantage of this MET-pIRIR procedure over the one-step pIRIR procedure is that it provides an alternative way for diagnosing whether a non-fading signal has been achieved or not, i.e. it is expected that the equivalent dose or age will increase as a function of stimulation temperature in this procedure, and a plateau should be reached if a non-fading signal is obtained.

\section{The MET-pIRIR signal}

\subsection{The decay curves of MET-pIRIR signals under IR stimulation}


Typical decay curves of the MET-pIRIR signals from sample WG3 are shown in Fig. 2. The initial intensity of IRSL at $50{ }^{\circ} \mathrm{C}$ is the strongest, and the initial intensity of the MET-pIRIR signals increased gradually toward higher temperatures. The intensity of the signal was significantly increased when raising the stimulation temperature by $50^{\circ} \mathrm{C}$ at each step. Such a thermal dependence can be explained as a result of thermal assistance effect (e.g. Bailiff and Poolton, 1991; Bailiff and Barnett, 1994; Meisl and Huntley, 2005; Li, 2010). Li and Li (2011) reported that the MET-pIRIR signals obtained at different temperatures have different thermal stabilities, which was explained as that at least two groups of traps were involved in the production of IRSL. They argued that the initial part of IRSL signal obtained at $50^{\circ} \mathrm{C}$ is mainly from shallow traps while the MET-pIRIR signals obtained at elevated temperatures $\left(200{ }^{\circ} \mathrm{C}\right)$ is mainly from deep traps, suggesting a preferentially bleaching of the shallow traps compared to the deep traps under IR stimulation ( $\mathrm{Li}$ and $\mathrm{Li}, 2011$ ). However, Jain and Ankjærgaard (2011) suggested that the difference in thermal stabilities between IRSL and pIRIR signals could be explained using a single-trap model, in which the distance of the electron-hole pairs is governing the thermal stability of IRSL signal, i.e. low temperature IRSL is raised from the recombination of relatively proximal pairs but pIRIR at elevated temperature is raised from distant pairs.

\subsection{The bleaching of MET-pIRIR signal}

The bleaching rate for the MET-pIRIR signals proposed for this protocol was tested using a sunlight simulator. In this test, 9 groups of aliquots with natural signal from WG3 and each group consists of 3 aliquots were prepared. Different groups were bleached using the sunlight simulator for different periods up to $1 \mathrm{hr}$. The aliquots were then measured using the protocol of Table 2 .

The residual IRSL and MET-pIRIR signals at different temperatures after sunlight simulator bleaching for different periods were shown in Fig. 3(a). It is shown that all signals can be bleached by sunlight simulator, but at different bleaching rates. The IRSL signal at $50^{\circ} \mathrm{C}$ was bleached at the 
fastest rate and the bleaching rate decreases as the stimulation temperature raised (Fig. 3(a)). There was only $2 \%$ of the initial signal left after $1 \mathrm{hr}$ bleaching for the IRSL at $50^{\circ} \mathrm{C}$, while $12 \%$ was still remaining for the signal measured at $250^{\circ} \mathrm{C}$ (Fig. 3(a)). A similar trend was observed for the residual doses (Fig. 3(b)). After $1 \mathrm{hr}$ bleaching, the residual doses for the IRSL signal at 50 and $250^{\circ} \mathrm{C}$ became $0.9 \pm 0.4$ and $4.5 \pm 1.0 \mathrm{~Gy}$, respectively, which are equivalent to a few hundred years and 1-2 ka in age for the two signals from a typical sediment with a dose rate of $\sim 3 \mathrm{~Gy} / \mathrm{ka}$. We have also tested the bleaching using an older sample Sm0404 (with an age of $\sim 100 \mathrm{ka}$ ). It was found that bleaching by the solar simulator for $1 \mathrm{hr}$ can result in a residual dose of $\sim 3.6 \mathrm{~Gy}$ for the MET-pIRIR signal at $250^{\circ} \mathrm{C}$, which is similar to the results obtained for the younger sample WG3 ( $13 \mathrm{ka})$.

To further support the conclusion that the MET-pIRIR signals are bleachable, a modern sand dune sample WG1 was measured. Previous study on quartz OSL from this sample gave an age of $\sim 40$ years with a $D_{e}$ value of $0.14 \pm 0.04$ Gy (Li et al., 2002). Fig. 4 shows the $D_{e}$ values for different IRSL signals at different temperatures using the protocol of Table 2. There are larger residual doses for the MET-pIRIR signals observed at higher stimulation temperatures. A residual dose of $0.5 \pm 0.1$ Gy was obtained for the IRSL signal measured at $50^{\circ} \mathrm{C}$, while a larger value of $2.4 \pm 1.5$ Gy was obtained for the MET-pIRIR signal measured at $250^{\circ} \mathrm{C}$. Based on these results, we conclude that the MET-pIRIR signals are bleachable by sun light. The higher residual dose observed at higher stimulation temperatures probably indicate a different origin of traps with different bleaching rate (the hightemperature signals are relatively harder to bleach than the signals measured at lower temperatures), but a higher thermal transfer to the traps associated with the MET-pIRIR signals also cannot be ruled out.

\section{Anomalous fading}

\subsection{Laboratory fading test}


In the study of the thermal stability of the IRSL and MET-pIRIR signals, Li and Li (2011) suggested that the IRSL are associated with easy-to-fade traps and the MET-pIRIR signals are associated with hard-to-fade traps. It is thus expected that the anomalous fading rates of the METpIRIR signals may be different from that of the $50^{\circ} \mathrm{C}$ IRSL signal. Previous studies on pIRIR signals have shown that the g-value depends on the stimulation temperature (Thomsen et al 2008; Thiel et al 2010). To test this using the MET-pIRIR signals, anomalous fading tests were conducted using Kfeldspar grains from sample HLD3. A single-aliquot measurement procedure similar to those described by Auclair et al. (2003), but based on the protocol of Table 2, was applied. In this experiment, the decay in the sensitivity-corrected MET-pIRIR signals $\left(\mathrm{L}_{\mathrm{x}\left(\mathrm{t}^{\circ} \mathrm{C}\right)} / \mathrm{T}_{\mathrm{x}\left(\mathrm{t}^{\circ} \mathrm{C}\right)}\right)$ as a function of storage time at room temperature were measured, where $\mathrm{L}_{\mathrm{x}\left(t^{\circ} \mathrm{C}\right)}$ is the IRSL response to a laboratory dose of 160 Gy measured at temperature $\mathrm{t}^{\circ} \mathrm{C}$ and $\mathrm{T}_{\mathrm{x}\left(\mathrm{t}^{\circ} \mathrm{C}\right)}$ is the response to a test dose of $8 \mathrm{~Gy}$. Preheating $\left(300{ }^{\circ} \mathrm{C}\right.$ for $\left.10 \mathrm{~s}\right)$ was applied immediately after each irradiation. The signals $\mathrm{L}_{\mathrm{x}\left(\mathrm{t}^{\circ} \mathrm{C}\right)}$ and $\mathrm{T}_{\mathrm{x}\left(\mathrm{t}^{\circ} \mathrm{C}\right)}$ were calculated from the integrated photon counts observed in the first $2 \mathrm{~s}$ of stimulation, with subtraction of a background signal derived from the last $5 \mathrm{~s}$ of the $100 \mathrm{~s}$ stimulation. The first measurement of the IRSL signal at $50^{\circ} \mathrm{C}$ took place at a time $t_{c}=1200 \mathrm{~s}$ after the mid-point of the irradiation time. It is noted that the first delay time $\left(t_{c}\right)$ is different for the signals measured at different temperatures because the signals had to be measured one by one. The same dose was then given repeatedly with different delay periods between the end of preheat and the start of the subsequent IRSL measurement.

The decay of the IRSL signals at different stimulation temperatures as a function of storage time (t) is shown in Fig. 5(a). The corresponding anomalous fading rates (g-value) were also calculated based on the data sets and they are shown in Fig. 5(b). The results show that the highest anomalous fading rate is observed for the $50^{\circ} \mathrm{C}$ IRSL $(4.6 \pm 0.7 \%)$, and it decreases as the stimulation temperature increased and negligible anomalous fading rates were observed for the signals obtained at $200^{\circ} \mathrm{C}(0.4 \pm 0.7 \% /$ decade $)$ and $250^{\circ} \mathrm{C}(-0.2 \pm 0.6 \% /$ decade $)$ (Fig. $\left.5(\mathrm{~b})\right)$. 


\subsection{Fading correction}

The above laboratory fading test results indicate that the MET-pIRIR signals at 200 and 250 ${ }^{\circ} \mathrm{C}$ may have negligible anomalous fading rates. To further confirm this conclusion, four natural aliquots of the same sample HLD3 were measured using the protocol in Table 2. The $\mathrm{D}_{\mathrm{e}}$ values obtained for different MET-pIRIR signals were used to calculate the corresponding ages and these ages were then corrected for anomalous fading based on the g-values from Fig. 5(b) using the procedure described by Hunley and Lamothe (2001). The apparent ages (blue diamonds) and fadingcorrected ages (red squares) with comparison of the quartz OSL age (yellow shading area) are shown in Fig. 5(c). Significant underestimation $(23 \%)$ in age was obtained for the $50^{\circ} \mathrm{C}$ IRSL signal. However, the apparent ages for the $50^{\circ} \mathrm{C}$ IRSL and MET-pIRIR signals increase as a function of stimulation temperature. Consistent ages were obtained for temperatures of 200 and $250{ }^{\circ} \mathrm{C}$ without fading correction, which are also in agreement with the quartz OSL age (yellow shaded area in Fig. 5(c)), indicating that the anomalous fading is negligible for the MET-pIRIR signals measured at 200 and $250^{\circ} \mathrm{C}$.

It is interesting to note that when the apparent ages were corrected for anomalous fading, over-correction in age was observed for the signals at $50^{\circ} \mathrm{C}$, and the corrected ages decrease with the stimulation temperature. Similar phenomena of over-correction in young samples were also observed by Reimann et al. (2011). The fading-corrected ages at $200{ }^{\circ} \mathrm{C}$ are consistent with the apparent ages and quartz OSL ages for the signals at 150,200 and $250^{\circ} \mathrm{C}$ (Fig. 5(c)). Similar phenomena of overcorrection in young sediments have been reported by other studies (Li et al., 2007a; Wallinga et al., 2007; Li et al., 2008; Reimann et al., 2011). Hence, the laboratory measured g-value may not necessarily represent the true anomalous fading rate in natural process, and fading correction should be cautious especially in the cases that large g-values ( $>\sim 5 \% /$ decade) are obtained in laboratory fading tests. 


\subsection{Fading for field saturated sample}

For the field-saturated samples (e.g. Sm8), an equilibrium between electron filling and escaping has been reached. This sample is expected to have received a natural dose of $\sim 1600$ Gy but a significantly lower equivalent dose of $\sim 670$ Gy was obtained for the $50^{\circ} \mathrm{C}$ IRSL measurements (Li and $\mathrm{Li}, 2008$ ). This is mainly due to the low environmental dose rate compared to that in laboratory, i.e. the probability of fading via tunnelling is higher than that of trap filling ( $\mathrm{Li}$ and $\mathrm{Li}, 2008$ ). As a result, a proportion of traps remain unfilled over geological period and the extent of unfilling depends on the environmental dose rate and anomalous fading rate. When these samples were irradiated in laboratory with a higher dose rate (by a factor of $\sim 10^{10}$ ), those traps remaining empty in burial will be filled, which is manifested by increase in luminescence signals. Hence, a larger increase in luminescence signal above the natural level after laboratory irradiation would indicate a higher anomalous fading rate in the corresponding traps, and vice versa.

Here we investigate the MET-pIRIR signal of natural sample $(\mathrm{N})$ and laboratory irradiated natural sample $(\mathrm{N}+\beta)$ using Sm8. Six aliquots of sample $\mathrm{Sm} 8$ were given a laboratory dose $(\beta)$ of 216 Gy in addition to their natural dose $(\mathrm{N}+\beta)$ and followed by a preheat of $300^{\circ} \mathrm{C}$ for $10 \mathrm{~s}$. The resultant signals $\left(\mathrm{L}_{\mathrm{N}+\beta}\right)$ at different stimulation temperatures were then measured, followed by giving a test dose to normalize inter-aliquot variations using a similar procedure of Table 2. Another six aliquots with only natural signals $\left(\mathrm{L}_{\mathrm{N}}\right)$ were then measured using a similar procedure.

The results of normalized $L_{N}$ and $L_{N+\beta}$ are shown in Fig. 6 . The laboratory dose $(\beta=216$ Gy) has resulted in a $\sim 20 \%$ increase in IRSL signal at $50^{\circ} \mathrm{C}$ compared to the natural signal (normalized to 1). But the discrepancy between $\mathrm{L}_{\mathrm{N}}$ and $\mathrm{L}_{\mathrm{N}+\beta}$ decreased as the stimulation temperature increased; it became $8 \%$ and $7 \%$ for the signals observed at 100 and $150{ }^{\circ} \mathrm{C}$, respectively, and no distinctive increase was observed for the signals measured at 200 and $250^{\circ} \mathrm{C}$ (Fig. 6). This result clearly 
demonstrates a higher anomalous fading in the signals measured at low temperatures (e.g. $50^{\circ} \mathrm{C}$ ) but a negligible anomalous fading for the MET-pIRIR signals at 200 and $250^{\circ} \mathrm{C}$.

\section{Performance of the protocol}

\subsection{Dose response curves}

The dose response curves (DRCs) for the MET-pIRIR signals were obtained using the protocol of Table 2. Fig. 7 shows the typical sensitivity-corrected DRCs and corresponding natural intensities at different stimulation temperatures for sample SM8. The DRCs are similar for the signals measured at 50,100 and $150{ }^{\circ} \mathrm{C}$, while an earlier saturation was observed for the signal of 200 and $250^{\circ} \mathrm{C}$. It is noted that such tendency of early saturation in $250^{\circ} \mathrm{C}$ are commonly observed for our samples investigated. The earlier saturation of the high temperature signals was also noted by Thomsen et al. (2010). The dose response curves can be fitted with single saturating exponentials. The different DRC shape of the $250{ }^{\circ} \mathrm{C}$ signal indicate that they are probably originated from different traps with the signals observed at low temperatures.

The $D_{0}$ values obtained by fitting the dose response curves in Fig. 7 are 440, 424, 450, 424 and 320 Gy for $50,100,150,200$ and $250{ }^{\circ} \mathrm{C}$, respectively. If the value of $2 \mathrm{D}_{0}$ were taken as the accurate upper dating limit (Wintle and Murray, 2006), an upper age limit of 200-300 ka might be expected for the signal measured at 200 and $250^{\circ} \mathrm{C}$ for a dose rate of $\sim 3 \mathrm{~Gy} / \mathrm{ka}$. It is interesting to note that the natural intensities of the signals at the 200 and $250^{\circ} \mathrm{C}$ are the same to or close to the laboratory saturation levels (see dashed lines in Fig. 7). The natural intensities of the signals 200 and $250^{\circ} \mathrm{C}$ are $96 \%$ and $100 \%$ of the saturation levels of the laboratory dose response curves, respectively. This result supports the conclusion that the MET-pIRIR signals at 200 and $250^{\circ} \mathrm{C}$ has a negligible anomalous fading for this sample.

Routine tests of recycling ratio and recuperation (or the ratio between the signal responses of zero dose and natural dose) can be obtained in construction of DRCs during $\mathrm{D}_{\mathrm{e}}$ measurements. The 
recycling ratios for all the samples falling within the range of $1.0 \pm 0.1$ and most of them are within $1.0 \pm 0.05$, suggesting that the sensitivity correction is robust. For the recuperation, there is a higher recuperation for the MET-pIRIR signals measured at higher temperature, e.g. the recuperation is highest for the $250^{\circ} \mathrm{C}$ signal. The level of recuperation is also dependent on the amplitude of the natural dose, e.g. younger samples tend to have a higher recuperation as it is expressed as percentage of the natural signal. For the young samples (WG2, WG3, HLD3, SGDL10, SGDL11 and SY3) investigated in this study, the recuperation values for the $250^{\circ} \mathrm{C}$ signal are generally less than $5 \%$, which is considered acceptable (Murray and Wintle, 2000). The values for other samples and lowtemperature signals are much smaller.

\subsection{Dose recovery tests}

The reliability of $\mathrm{D}_{\mathrm{e}}$ estimation can be tested using a dose recovery experiment (Murray and Roberts, 1998; Wallinga et al., 2000). This test involves giving a known laboratory dose to bleached aliquots. The given dose is then measured as an 'unknown' dose using the protocol proposed in Table 2. In this study, two approaches were adopted to evaluate the ability of dose recovery of the protocol. In the first test, five aliquots of sample WG3 were bleached for $1 \mathrm{hr}$ using sunlight simulator before a laboratory dose of 84 Gy was given to them. After that, these aliquots were immediately measured using the protocol of Table 2. The measured to given dose ratios (or recovered dose ratios) for different IRSL and MET-pIRIR signals were shown in Fig. 8(a). It is shown that recovered dose ratios of around 0.9 were obtained for the 50 and $100{ }^{\circ} \mathrm{C}$ signals. The ratio increase to $0.97 \pm 0.03,1.02 \pm 0.03$ and $1.05 \pm 0.04(\mathrm{n}=5)$ for the signals at 150,200 and $250^{\circ} \mathrm{C}$, respectively. However, if the residual doses after $1 \mathrm{hr}$ bleaching of sunlight simulator (Fig. 3(b)) were taken into account and are subtracted from the measured doses, the recovered dose ratio became $0.89,0.89,0.94,0.98$ and 1.00 for the signals at $50,100,150,200$ and $250^{\circ} \mathrm{C}$, respectively (Fig. 8(a)). 
In the second test, 12 aliquots of the modern sand sample WG1 were given a dose of $21.6 \mathrm{~Gy}$. These aliquots were then divided into four groups and then each group was stored in the dark for different periods before dose measurements using the protocol of Table 2. The measured doses were then corrected for residual doses from the data set in Fig. 4. The recovered dose ratios for different signals as a function of delay time were shown in Fig. 8(b). It clearly shows that there is a falling trend of the recovered dose ratio for the $50^{\circ} \mathrm{C}$ IRSL signal as a function of delay time, which is expected as a result of anomalous fading effect. In addition, there is a significant underestimation in dose recovery for the signal measured at $50^{\circ} \mathrm{C}$. However, such underestimation and falling trend was reduced by using the signals measured at high temperatures. The overall average dose recovery ratios for different delay periods are $0.77 \pm 0.07,0.90 \pm 0.04,0.90 \pm 0.02,0.97 \pm 0.05$ and $0.92 \pm 0.05$ for the signals at $50,100,150,200$ and $250^{\circ} \mathrm{C}$, respectively (Fig. $8(\mathrm{~b})$ ). The above dose recovery tests demonstrate that the IRSL signals measured at 200 and $250^{\circ} \mathrm{C}$ give the best dose recovery result and also there are negligible anomalous fading effects for them.

\subsection{Preheat plateau test}

The suitability of the preheating temperature used in the protocol can be tested by investigating if there is any dependence of $D_{e}$ upon preheating temperatures, the so-called preheating plateau test (Murray and Roberts, 1998; Murray and Wintle, 2000). This can be done by measuring the $D_{e}$ values using a range of preheating temperatures in step 2 (Table 2). The $D_{e}$ values are then plotted against the preheating temperatures. A preheat temperature within a 'plateau' region should be used as appropriate preheating temperature. Here we investigated the preheat plateau test using both dose recovery and $D_{e}$ measurements with preheat temperature ranging from 220 to $300^{\circ} \mathrm{C}$ in step of $20^{\circ} \mathrm{C}$. In order to avoid significant effect from TL signal during IRSL measurement at elevated temperature $\left(>200^{\circ} \mathrm{C}\right)$ for low preheat temperatures, we omit the measurement of IRSL at $250^{\circ} \mathrm{C}$ (steps 7 and 15) and only measure the signals at 50,100, 150 and $200^{\circ} \mathrm{C}$. We also adopted a 
preheating time of $60 \mathrm{~s}$, instead of $10 \mathrm{~s}$, in order to further reduce the influence of TL to IRSL measurements at lower preheat temperatures.

In the dose recovery test, 15 aliquots of WG3 were bleached for $1.5 \mathrm{hr}$ using a sunlight simulator before giving a dose of $84 \mathrm{~Gy}$. These aliquots were then measured using the protocol of Table 2 with different preheating temperatures. The recovered dose ratios for different signals as a function of preheat temperature are shown in Fig. 9(a). It is shown that there was a trend of decrease in the recovered dose ratio for the signals at 50 and $100{ }^{\circ} \mathrm{C}$ as the preheating temperature increased. Also, there is a significant underestimation in the recovered dose for these signals especially at the preheating temperature from 260 to $300^{\circ} \mathrm{C}$, where the dose recovery ratios are less than 0.9 (Fig. 9(a)). Such underestimation and preheat-dependence were reduced by using the signals measured at high temperatures, i.e. 150 and $200^{\circ} \mathrm{C}$. Particularly, no dependence of the recovered dose ratio on the preheat was observed for the signal obtained at $200^{\circ} \mathrm{C}$, and the dose recovered ratios are consistent with unity for all preheat temperatures investigated (Fig. 9(a)). It is noted that the dose recovery results improve (increase towards unity) with stimulation temperature (Fig. 8). This is the same trend as is observed on the preheat plateaus in Fig. 9, suggesting that at least some of this trend arises from inaccurate measurement of equivalent dose.

In the second test, the natural signal from sample WG3 were measured in a similar way as used in the dose recovery test described above. The $\mathrm{D}_{\mathrm{e}}$ values and corresponding ages obtained for different signals as a function of preheat temperature are shown in Fig. 9(b). For comparison, the quartz OSL age (13.2 $\pm 0.8 \mathrm{ka})$ was shown in yellow shaded area. A similar pattern as the dose recovery result (Fig. 9(a)) was obtained. Remarkable underestimation in ages was observed for the signals at 50 and $100{ }^{\circ} \mathrm{C}$ and there is decreasing trend in age as the preheating temperature was raised. However, such dependence disappeared for the signal observed at $200{ }^{\circ} \mathrm{C}$, and the ages obtained are excellently consistent with quartz OSL age (Fig. 9(b)). The above results further confirm that the 
MET-pIRIR signal observed at $200{ }^{\circ} \mathrm{C}$ gives the most reliable result and there is negligible anomalous fading for the signals.

\section{Dating sediments using MET-pIRIR signals}

We tested the protocol of Table 3 by dating various samples with different ages in the range of 0-120 ka. These samples were extensively studied previously using quartz OSL and IRSL isochron methods ( $\mathrm{Li}$ et al., 2002; $\mathrm{Li}$ et al., 2008). The results of applying the protocol to all the samples are summarized in Table 3.

Fig. 10 shows the typical plots of ages obtained for different MET-pIRIR signals plotted against stimulation temperatures for four samples, in comparison with expected ages, e.g. quartz OSL ages (SY3, WG3 and SGDL11) and expected age (Sm0404), shown as yellow shaded area. It is shown that the IRSL ages obtained at $50{ }^{\circ} \mathrm{C}$ are underestimated, which can be explained as a result of anomalous fading effect ( $\mathrm{Li}$ et al., 2007a, 2008). The ages tend to increase as the stimulation temperature increased and an age plateau has reached at the temperatures 200 and $250{ }^{\circ} \mathrm{C}$, which are also consistent with the expected ages (yellow shaded area). Based on this result and the dose recovery tests in Fig. 9, we adopt the ages obtained using the $200^{\circ} \mathrm{C}$ signal as an estimation of the true age for the K-feldspar samples investigated without anomalous fading correction.

In Fig. 11, the ages based on the MET-pIRIR signals at $200{ }^{\circ} \mathrm{C}$ and $250{ }^{\circ} \mathrm{C}$ and IRSL at $50{ }^{\circ} \mathrm{C}$ for all samples investigated are plotted as a function of the expected ages based on quartz OSL ages or expected ages (Table 3). All data are plotted in Figure 11(a) and only data for samples younger than $25 \mathrm{ka}$ in Fig. 11(b). The ages based on $50^{\circ} \mathrm{C}$ IRSL measurements (red squares) for these samples are underestimated for most of the samples, indicating the anomalous fading of the $50^{\circ} \mathrm{C}$ IRSL signal. However, there is a good agreement between the MET-pIRIR $200^{\circ} \mathrm{C}$ and $250^{\circ} \mathrm{C}$ ages (blue diamonds and green triangles) and the expected ages for all samples. This agreement supports the assertion that 
use of the MET-pIRIR $200^{\circ} \mathrm{C}$ and $250{ }^{\circ} \mathrm{C}$ signals and the protocol of Table 2 results in right ages. This confirms the conclusion that the MET-pIRIR $200^{\circ} \mathrm{C}$ and $250{ }^{\circ} \mathrm{C}$ signals suffers from negligible anomalous fading and can be used to evaluate the K-feldspar age without fading correction.

\section{Further tests on the protocol}

Using the protocol outlined in Table 2, we obtain IRSL signals repeatedly by progressively increasing the stimulation temperatures in step of $50^{\circ} \mathrm{C}$, e.g. $50,100,150,200$ and $250^{\circ} \mathrm{C}$. Although this stimulation procedure appears to give a reliable result for the signals observed at $200^{\circ} \mathrm{C}$ and 250 ${ }^{\circ} \mathrm{C}$ according to the dose recovery tests and age evaluation for different samples (Fig. 11), it is necessary to explore whether this procedure for stimulating IRSL signals is the most appropriate. Here we investigate the effect of keeping the number of IR stimulation the same (5 stimulation) but changing the IR stimulation temperature increment to $25^{\circ} \mathrm{C}$ instead of $50^{\circ} \mathrm{C}$, i.e. using $50,75,100$, 125 and $150^{\circ} \mathrm{C}$ as the IRSL temperatures in steps 3-7 and 10-14 of Table 2 instead of 50, 100, 150, 200 and $250^{\circ} \mathrm{C}$. In Fig. 12, the ages obtained at different temperatures for sample WG3 are shown, in comparison with the quartz OSL age (yellow shaded area), which clearly demonstrates age underestimation at all temperatures. This result indicates that IR bleaching time is not as crucial as selection of stimulation temperature for reducing anomalous fading.

Another test is to investigate if the multiple IR measurements from progressively elevating stimulation temperatures are necessary. Three groups of four aliquots from FJGW1 were measured using the one-step pIRIR procedure similar to that proposed by Thomsen et al. (2008) but using different stimulation temperatures and periods in both IRSL and pIRIR measurements. In this study, the first IRSL measurement was conducted at 50,100 and $150{ }^{\circ} \mathrm{C}$ after preheat at $300^{\circ} \mathrm{C}$ for $10 \mathrm{~s}$ for each of the groups, respectively. It is noted that a stimulation period of $300 \mathrm{~s}$, equivalent to the cumulative stimulation period in step 3-5 of Table 2, was used for the first IRSL measurement. After that the pIRIR signal was measured at $200{ }^{\circ} \mathrm{C}$. The ages obtained for the $200{ }^{\circ} \mathrm{C}$ pIRIR signals are $45.0 \pm 2.1,45.2 \pm 2.6$ and $46.6 \pm 1.7 \mathrm{ka}$ for the three groups, respectively. These values are 
underestimated when compared to those values obtained using MET-pIRIR procedure $(52.6 \pm 1.8$ and $56.0 \pm 5.1 \mathrm{ka}$ for the MET-pIRIR signals at 200 and $250^{\circ} \mathrm{C}$, respectivley), quartz OSL $(55.7 \pm 1.0 \mathrm{ka})$ and isochron method (54 $\pm 7 \mathrm{ka}$ ) (Fan et al. 2011). We also investigated the one-step pIRIR procedure using the same sample based on the first IRSL measured at $50{ }^{\circ} \mathrm{C}$ for $400 \mathrm{~s}$ after preheat at $300^{\circ} \mathrm{C}$ for $10 \mathrm{~s}$ and the pIRIR measured at $250^{\circ} \mathrm{C}$. The pIRIR age obtained is $45.3 \pm 1.6 \mathrm{ka}$, which is also underestimated. Thiel et al. (2010) showed that the pIRIR signal at $290{ }^{\circ} \mathrm{C}$ from a field saturated sample is close to the saturation level of laboratory dose response curve, indicating that the fading of such signal might be negligible in nature, although they detected a small fading rate $(\sim 1 \%)$ for their signals from laboratory irradiated samples. Here we have explored the performance of the pIRIR signal at $290^{\circ} \mathrm{C}$ for our sample FJGW1 using the same procedures as Thiel et al. (2010). An underestimated age of $46.7 \pm 2.4 \mathrm{ka}$ was obtained, indicating that the stable signal was not isolated for our sample using this method. In summary, we concluded that the procedure of progressively increasing stimulation temperature proposed in Table 2 is necessary to gradually discriminate fading and non-fading signals, and the temperature increment of $50{ }^{\circ} \mathrm{C}$ used for IR stimulation in Table 2 is a reasonable choice for achieving non-fading signals.

\section{Conclusions}

A protocol of measuring the IRSL signal from K-feldspars by progressively increasing the stimulation temperature from 50 to $250^{\circ} \mathrm{C}$ in step of $50^{\circ} \mathrm{C}$, so called MET-pIRIR signals, was proposed. The IRSL obtained at $50^{\circ} \mathrm{C}$ has the highest anomalous fading rate, and the fading rate decreases as the stimulation temperature increases from 100 to $200^{\circ} \mathrm{C}$. Negligible anomalous fading was observed for the MET-pIRIR signals obtained at 200 and $250^{\circ} \mathrm{C}$. The $\mathrm{D}_{\mathrm{e}}$ or ages increase progressively from $50^{\circ} \mathrm{C}$ to $200^{\circ} \mathrm{C}$, but similar values were obtained for the MET-pIRIR signal at 200 and $250^{\circ} \mathrm{C}$. The MET-pIRIR signals are bleachable and there are small residual doses (a few Gy) based on measurement of modern samples or bleached samples. The protocol has been tested using 
various sedimentary samples with different ages from different regions of China. The MET-pIRIR ages obtained at 200 and $250^{\circ} \mathrm{C}$ are consistent with independent and/or quartz OSL ages, and no fading-correction is required. Further tests of the wide applicability of this protocol to samples from the rest of the world are necessary.

\section{Acknowledgements}

Dr. Tsukamoto and Dr. Thomsen are appreciated for their critical comments on the manuscript. This study was financially supported by the grants to SHL from the Research Grant Council of the Hong Kong Special Administrative Region, China (Project no. 7035/06P, 7035/07P and $7028 / 08 \mathrm{P})$.

\section{References}

Aitken, M.J., 1985. Thermoluminescence dating. Academic press London.

Aitken, M.J., 1998. An Introduction to Optical Dating. Oxford University Press Oxford.

Auclair, M., Lamothe, M., Huot, S., 2003. Measurement of anomalous fading for feldspar IRSL using SAR. Radiation Measurements 37, 487-492.

Bøtter-Jensen, L., Andersen, C.E., Duller, G.A.T., Murray, A.S., 2003a. Developments in radiation, stimulation and observation facilities in luminescence measurements. Radiation Measurements 37, 535-541.

Bøtter-Jensen, L., McKeever, S.W.S., Wintle, A.G., 2003b. Optically Stimulated Luminescence Dosimetry. Elsevier Amsterdam.

Bailiff, I.K., Barnett, S.M., 1994. Characteristics of infrared stimulated luminescence from a feldspar at low temperatures. Radiation Measurements 23, 541-545.

Bailiff, I.K., Poolton, N.R.J., 1991. Studies of charge transfer mechanisms in feldspars. Nuclear Tracks and Radiation Measurements 18, 111-118.

Buylaert, J.P., Murray, A.S., Thomsen, K.J., Jain, M., 2009. Testing the potential of an elevated temperature IRSL signal from K-feldspar. Radiation Measurements 44, 560-565. 
Fan, A.C., Li, S.H., Li, B., 2011. Observation of unstable fast component in OSL of quartz. Radiation Measurements 46, 21-28.

Hütt, G., Jaek, I., Tchonka, J., 1988. Optical dating: K-feldspars optical response stimulation spectra. Quaternary Science Reviews 7, 381-385.

Huntley, D.J., Baril, M.R., 1997. The K content of the K-feldspars being measured in optical dating or in thermoluminescence dating. Ancient TL 15: 11-13.

Huntley, D.J., Hancock, R.G.V., 2001. The Rb contents of the K-feldspars being measured in optical dating. Ancient TL 19: 43-46.

Huntley, D.J., Lamothe, M., 2001. Ubiquity of anomalous fading in K-feldspars and the measurement and correction for it in optical dating. Canadian Journal of Earth Sciences 38, 1093-1106.

Huntley, D.J., Lian, O.B., 2006. Some observations on tunnelling of trapped electrons in feldspars and their implications for optical dating. Quaternary Science Reviews 25, 2503-2512.

Jain, M., Ankjærgaard, C., 2011. Towards a non-fading signal in feldspar: insight into charge transport and tunnelling from time-resolved optically stimulated luminescence. Radiation Measurements 46, 292-309.

Kars, R.H., Wallinga, J., Cohen, K.M., 2008. A new approach towards anomalous fading correction for feldspar IRSL dating - tests on samples in field saturation. Radiation Measurements 43, 786-790.

Lamothe, M., Auclair, M., 1999. A solution to anomalous fading and age shortfalls in optical dating of feldspar minerals. Earth and Planetary Science Letters 171, 319-323.

Lamothe, M., Auclair, M., Hamzaoui, C., Huot, S., 2003. Towards a prediction of long-term anomalous fading of feldspar IRSL. Radiation Measurements 37, 493-498.

Lai, Z.P., 2010. Chronology and the upper dating limit for loess samples from Luochuan section in the Chinese Loess Plateau using quartz OSL SAR protocol. Journal of Asian Earth Sciences 37, 176-185.

Li, B., 2010. The relationship between thermal activation energy, infrared stimulated luminescence and anomalous fading of K-feldspars. Radiation Measurements 45, 757-763.

Li, B., Li, S.H. 2011. Thermal stability of infrared stimulated luminescence of sedimentary Kfeldspar. Radiation Measurements, 46, 29-36.

Li, B., Li, S.H., Sun, J.M. Isochron dating of sand-loess-soil deposits from the Mu Us Desert margin, central China. Quaternary Geochronology, submitted.

Li, B., Li, S.H., 2008. Investigations of the dose-dependent anomalous fading rate of feldspar from sediments. Journal of Physics D-Applied Physics 41, 225502.

Li, B., Li, S.H., Wintle, A.G., Zhao, H., 2007a. Isochron measurements of naturally irradiated Kfeldspar grains. Radiation Measurements 42, 1315-1327. 
Li, B., Li, S.H., Wintle, A.G., Zhao, H., 2008. Isochron dating of sediments using luminescence of Kfeldspar grains. Journal of Geophysical Research-Earth Surface 113, F02026, doi:02010.01029/02007JF000900. .

Li, S.H., Chen, Y.Y., Li, B., Sun, J.M., Yang, L.R., 2007b. OSL dating of sediments from desert in northern China. Quaternary Geochronology 2, 23-28.

Li, S.H., Sun, J.M., 2006. Optical dating of Holocene dune sands from the Hulun Buir Desert, northeastern China. Holocene 16, 457-462.

Li, S.H., Sun, J.M., Zhao, H., 2002. Optical dating of dune sands in the northeastern deserts of China. Palaeogeography Palaeoclimatology Palaeoecology 181, 419-429.

Lu, Y.C., Wang, X.L., Wintle, A.G., 2007. A new OSL chronology for dust accumulation in the last 130,000 yr for the Chinese Loess Plateau. Quaternary Research 67, 152-160.

Meisl, N.K., Huntley, D.J., 2005. Anomalous fading parameters and activation energies of feldspars Ancient TL 23, 1-8.

Murray, A.S., Olley, J.M., 2002. Precision and accuracy in the optically stimulated luminescence dating of sedimentary quartz: a status review. Geochronometria 21, 1-16.

Murray, A.S., Roberts, R.G., 1998. Measurement of the equivalent dose in quartz using a regenerative-dose single-aliquot protocol. Radiation Measurements 29, 503-515.

Murray, A.S., Wintle, A.G., 2000. Luminescence dating of quartz using an improved single-aliquot regenerative-dose protocol. Radiation Measurements 32, 57-73.

Murray, A.S., Buylaert, J.P., Thomsen, K.J., Jain, M., 2009. The effect of preheating on the IRSL signal from feldspar. Radiation Measurements 44: 554-559, DOI 10.1016/j.radmeas.2009.02.004.

Poolton, N.R.J., Ozanyan, K.B., Wallinga, J., Murray, A.S., Bøtter-Jensen, L., 2002a. Electrons in feldspar II: a consideration of the influence of conduction band-tail states on luminescence processes. Physics and Chemistry of Minerals 29, 217-225.

Poolton, N.R.J., Wallinga, J., Murray, A.S., Bulur, E., Bøtter-Jensen, L., 2002b. Electrons in feldspar I: on the wavefunction of electrons trapped at simple lattice defects. Physics and Chemistry of Minerals 29, 210-216

Prescott, J.R., Hutton, J.T., 1994. Cosmic ray contributions to dose rates for luminescence and ESR dating: Large depths and long-term time variations. Radiation Measurements 23, 497-500.

Porter, S.C., An, Z.S., 1995. Correlation between Climate Events in the North-Atlantic and China during Last Glaciation. Nature 375, 305-308.

Reimann, T., Tsukamoto, S., Naumann, M., Frechen, M., 2011. The potential of using feldspars for optical dating of young coastal sediments - a test case from Darss-Zingst peninsula.

Quaternary Geochronology 6, 207-222. 
Sanderson, D.C.W., Clark, R.J., 1994. Pulsed photostimulated luminescence of alkali feldspars. Radiation Measurements 23, 633-639.

Spooner, N.A., 1992. Optical dating: Preliminary results on the anomalous fading of luminescence from feldspars. Quaternary Science Reviews 11, 139-145.

Spooner, N.A., 1994. The anomalous fading of infrared-stimulated luminescence from feldspars. Radiation Measurements 23, 625-632.

Sun, J.M., Ding, Z.L., Liu, T.S., Rokosh, D., Rutter, N., 1999. 580,000-year environmental reconstruction from aeolian deposits at the Mu Us Desert margin, China. Quaternary Science Reviews 18, 1351-1364.

Thiel, C., Buylaert., J.P., Murray, A.S., Terhost. B., Hofer, I., Tsukamoto, S., Frechen, M., 2010. Luminescence dating of the Stratzing loess profile (Austria) - Testing the potential of an elevated temperature post-IR IRSL protocol (Accepted in Quaternary International).

Thomsen, K.J., Murray, A.S., Jain, M., Botter-Jensen, L., 2008. Laboratory fading rates of various luminescence signals from feldspar-rich sediment extracts. Radiation Measurements 43, 1474-1486.

Thomsen, K.J., Murray, A.S., Jain, M., 2010. Stability of IRSL signals from sedimentary K-feldspar samples. Geochronometria. DOI 10.2478/s13386-011-0003-z

Tsukamoto, S., Denby, P.M., Murray, A.S., Botter-Jensen, L., 2006. Time-resolved luminescence from feldspars: New insight into fading. Radiation Measurements 41, 790-795.

Wallinga, J., Bos, A.J.J., Dorenbos, P., Murray, A.S., Schokker, J., 2007. A test case for anomalous fading correction in IRSL dating. Quaternary Geochronology 2, 216-221.

Wallinga, J., Murray, A., Duller, G., 2000. Underestimation of equivalent dose in single-aliquot optical dating of feldspars caused by preheating. Radiation Measurements 32, 691-695.

Wintle, A.G., 1973. Anomalous fading of thermoluminescence in mineral samples. Nature 245, 143144.

Wintle, A.G., 2008. Luminescence dating: where it has been and where it is going. Boreas 37, 471482.

Wintle, A.G., Murray, A.S., 2006. A review of quartz optically stimulated luminescence characteristics and their relevance in single-aliquot regeneration dating protocols. Radiation Measurements 41, 369-391.

Zhao, H., Li, S.H., 2002. Luminescence isochron dating: A new approach using different grain sizes. Radiation Protection Dosimetry 101, 333-338.

Zhao, H., Li, S.H., 2005. Internal dose rate to K-feldspar grains from radioactive elements other than potassium. Radiation Measurements 40: 84-93. 


\section{Figure captions}

2 Figure 1: Deserts and loess plateau in Northern China and sampling sites. Full circles are the

5 Figure 2: The IRSL and MET-pIRIR curves obtained for different stimulation temperature

6 (temperatures are shown above each curve) from sample WG3. All IRSL curves were

7 normalized using the initial intensity of IRSL signal (stimulation time at $\mathrm{t}=0$ ).

8

9 Figure 3: (a) Residual signals and (b) residual doses of sample WG3 as a function of bleaching

Figure 4: Residual doses of the MET-pIRIR signals at different stimulation temperatures for the modern sand dune sample WG1. The data were obtained using four aliquots.

Figure 5: (a) Anomalous fading test of the MET-pIRIR signals using four aliquots from sample HLD3 as a function of delayed period $(t)$ using the protocol of Table 2. The normalized signals were obtained using the delayed $\mathrm{L}_{\mathrm{x}\left(\mathrm{t}^{\circ} \mathrm{C}\right)} / \mathrm{T}_{\mathrm{x}\left(\mathrm{t}^{\circ} \mathrm{C}\right)}$ method similar to that described by Auclair et al. (2003). The normalized signals $\left(\mathrm{L}_{\mathrm{x}\left(\mathrm{t}^{\circ} \mathrm{C}\right)} / \mathrm{T}_{\mathrm{x}\left(t^{\circ} \mathrm{C}\right)}\right)$ were normalized to the first measurements $\left(t_{c}=1200,1430,1720,2070\right.$ and $2500 \mathrm{~s}$ for the signals at $50,100,150,200$ and $250^{\circ} \mathrm{C}$, respectively). (b) Anomalous fading rates (g-values) for the MET-pIR IRSL signals obtained based on the data sets in (a) plotted against stimulation temperatures. (c) The apparent ages (blue diamonds) obtained using the protocol of Table 3 and fading-corrected ages (red squares) 
1 based on the g-values in (b). The yellow shaded area shows the quartz OSL age (10.8 $\pm 1.2 \mathrm{ka})$.

2 The ages were obtained using four aliquots from sample HLD3.

4 Figure 6: Comparison of the MET-pIRIR signal of natural sample $\left(\mathrm{L}_{\mathrm{N}}\right)$ and laboratory

5 irradiated natural sample $\left(\mathrm{L}_{\mathrm{N}+\beta}\right)$ of $\mathrm{Sm} 8$. The data points at each stimulation temperature were

6 normalized using the corresponding value of $\mathrm{L}_{\mathrm{N}}$ at that temperature.

8 Figure 7: Natural intensities and dose response curves of the MET-pIRIR signal from sample

9 Sm8 obtained using the procedure of Table 2.The data points were fitted using single saturating

10 exponentials. Note that the error bars are too small to be overlapped by the symbols of data

11 points.

13 Figure 8: (a) The recovered dose ratios for different IRSL and MET-pIRIR signals from sample

14 WG3, which was bleached for $1 \mathrm{hr}$ using sunlight simulator before giving a laboratory dose of

1584 Gy and measured using the protocol of Table 2. The blue diamonds show the apparent

16 recovered dose ratios. The red squares show the corresponding ratios after correcting for

17 residual doses using the data from Fig. 3(b). (b) The recovered dose ratios for different IRSL

18 and MET-pIRIR signals from modern sand sample WG1, which was given a laboratory dose of

1921.6 Gy and measured using the protocol of Table 2. The data sets were obtained using five

20 aliquots.

22 Figure 9: (a) Dose recovery results for different IRSL and MET-pIRIR signals as a function of 23 preheat temperatures from 220 to $300^{\circ} \mathrm{C}$, using sample WG3. The sample were bleached for 1.5 
1 hour using solar simulator and then given a dose of 84 Gy before applying the procedure of

2 Table 3. (b) Preheat plateau test for the IRSL and MET-pIRIR signals from sample WG3. The

3 yellow shaded area shows the quartz OSL age (13.2 $\pm 0.8 \mathrm{ka})$. Note that the ages are plotted on

4 the left scale and equivalent dose on the right scale.

6 Figure 10: The ages of the MET-pIRIR signals for samples SY3, WG3, SGDL11 and Sm0404,

7 obtained using the protocol of Table 2 . The yellow shaded area in each plot shows the

8 corresponding quartz OSL age (see Table 2 for values).

10 Figure 11: (a) Comparison of the K-feldspar ages obtained using IRSL at $50^{\circ} \mathrm{C}$ and the MET-

11 pIRIR signals measured at the $200^{\circ} \mathrm{C}$ and $250^{\circ} \mathrm{C}$ with expected ages based on quartz OSL or

12 expected ages (see Table 2). (b) The enlarged scale of the square area in (a).

14 Figure 12: The ages obtained using $50,75,100,125$ and $150^{\circ} \mathrm{C}$ (blue diamonds) as the IRSL

15 temperatures in step 3-7 of Table 2 for sample WG3. The results obtained using temperatures

$1650,100,150,200$ and $250^{\circ} \mathrm{C}$ (red squares) are also shown for comparison. The yellow shaded

17 area shows the corresponding quartz OSL age (13.2 $\pm 0.8 \mathrm{ka})$.

18 
Figure 1

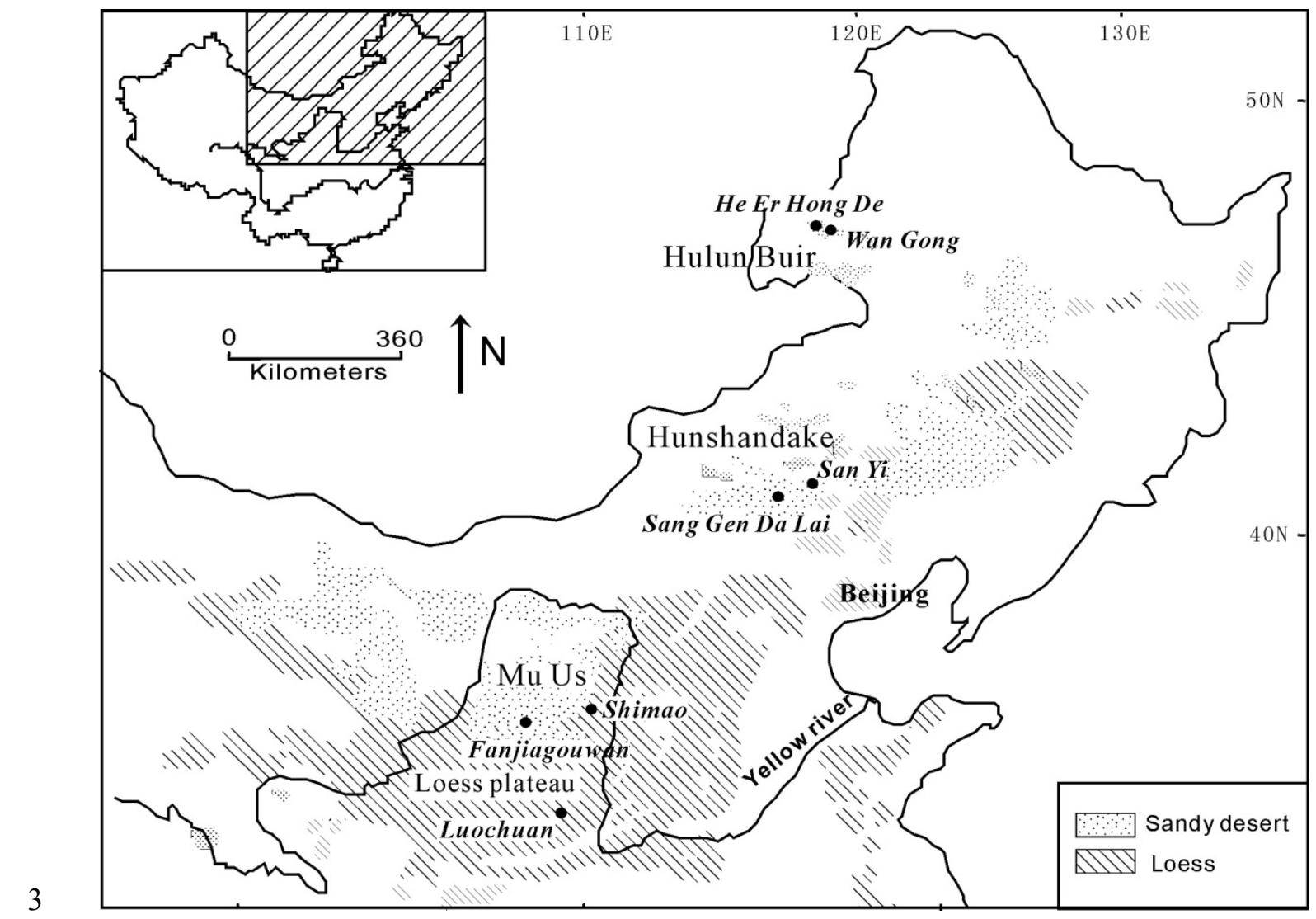


2 Figure 2

3

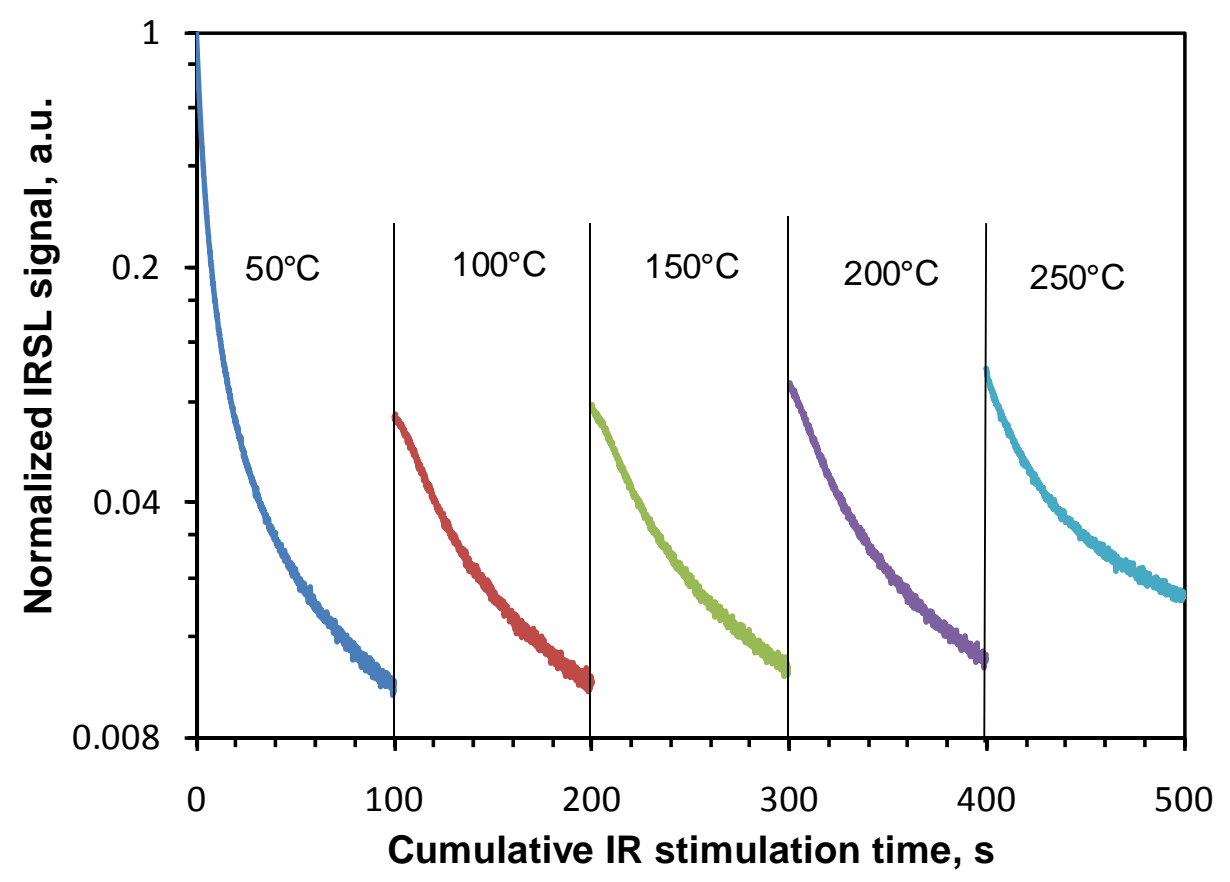

4

5

6

7 

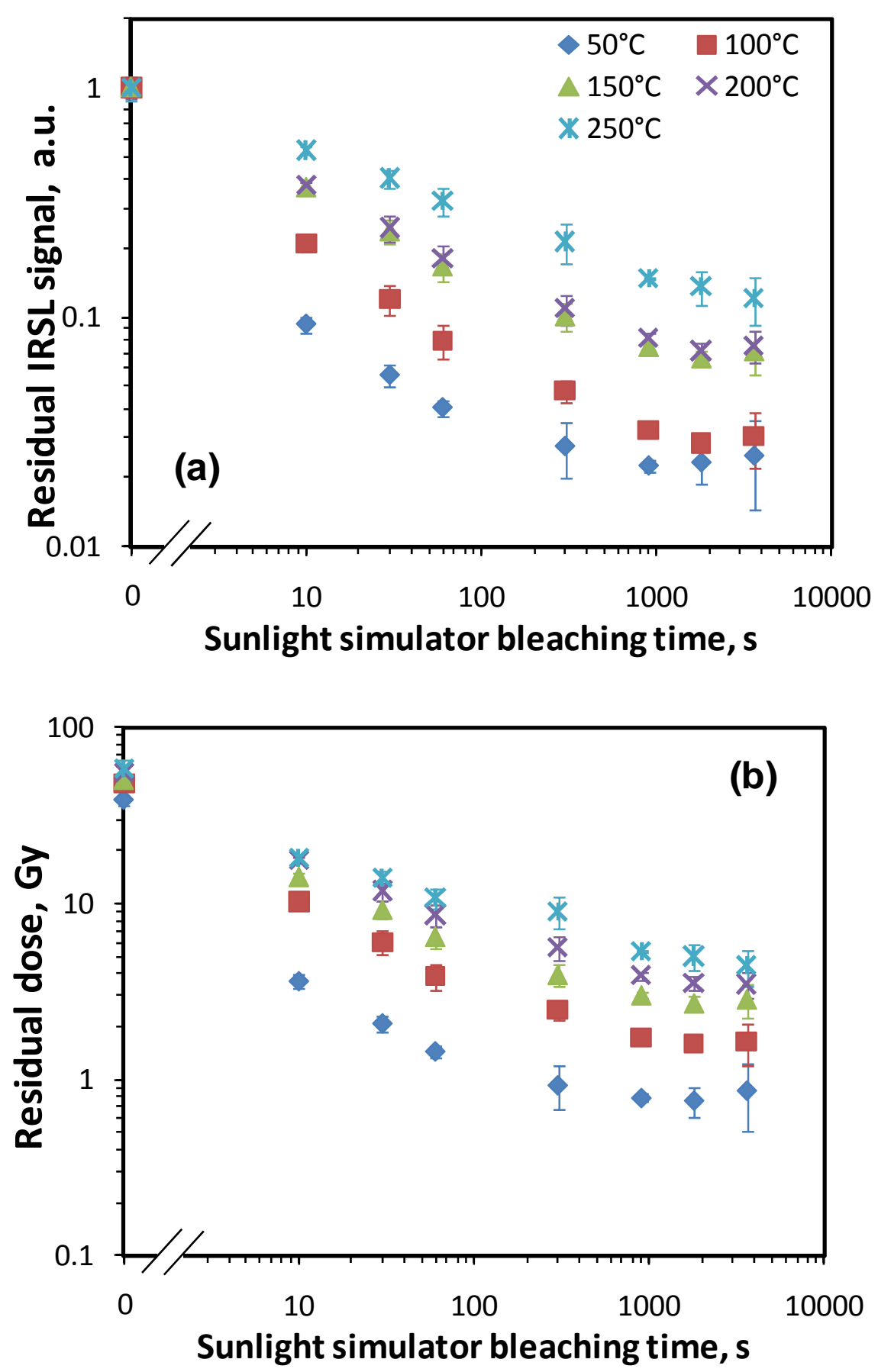


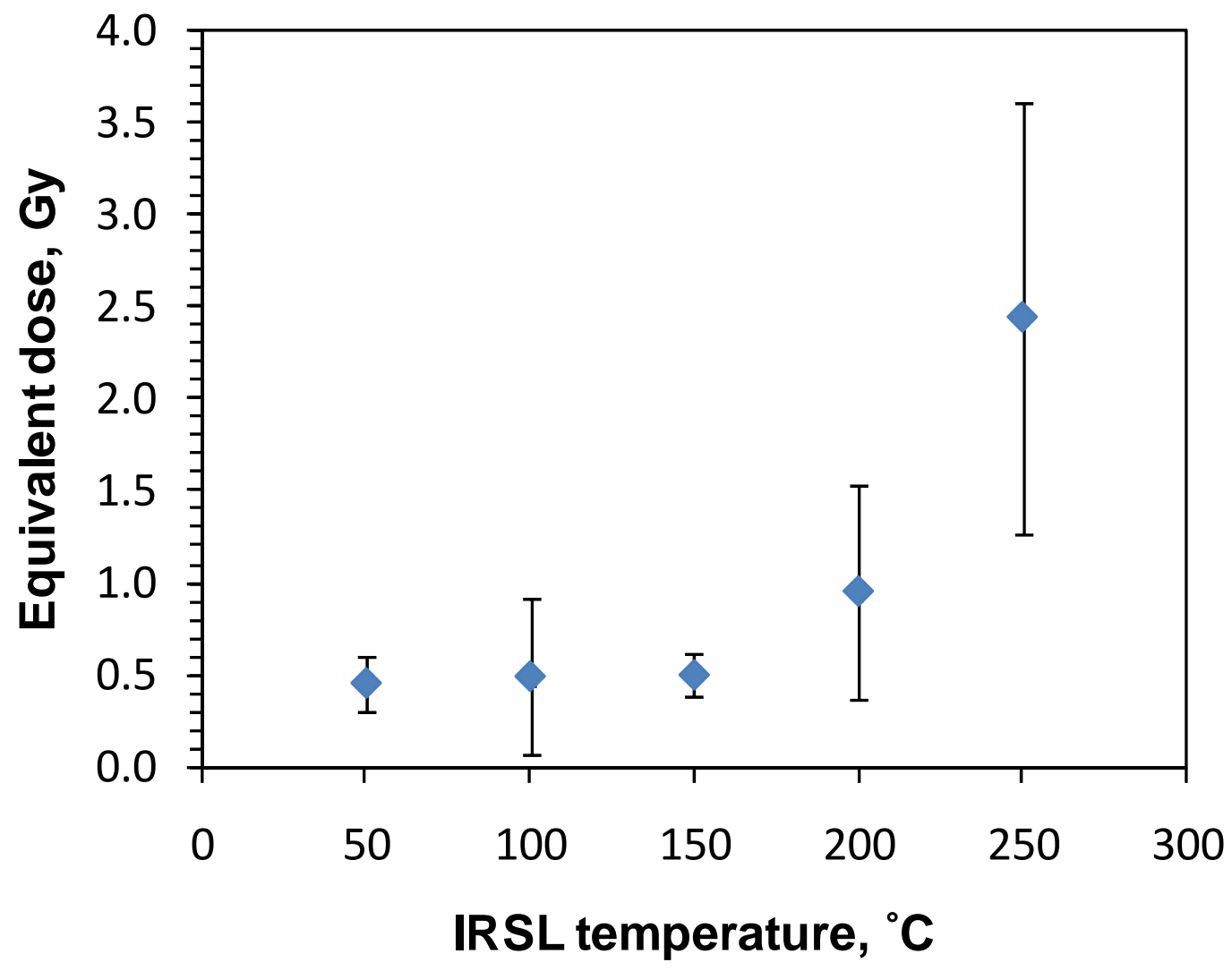

$3 \quad$ Figure 4 
1 Figure 5

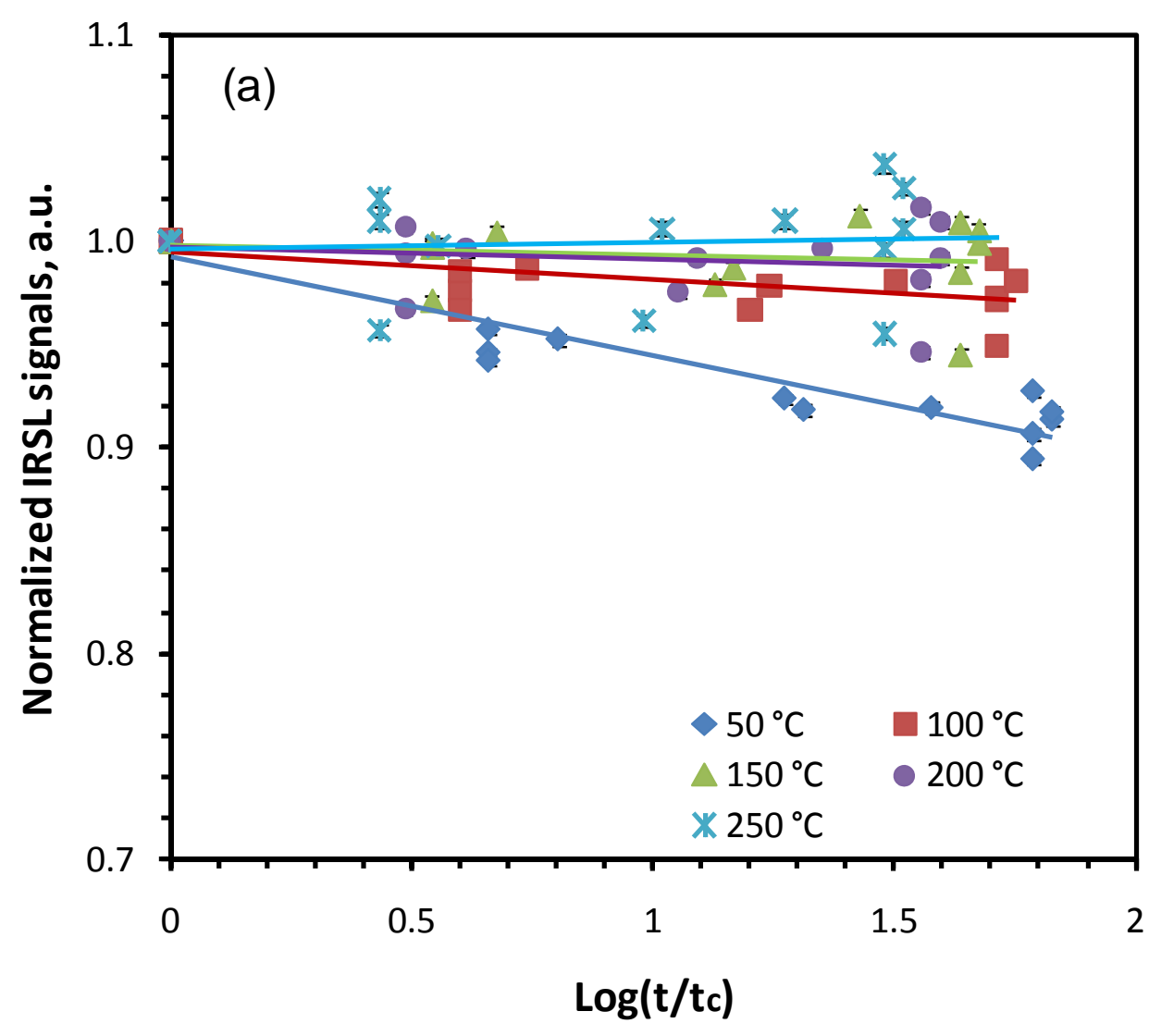



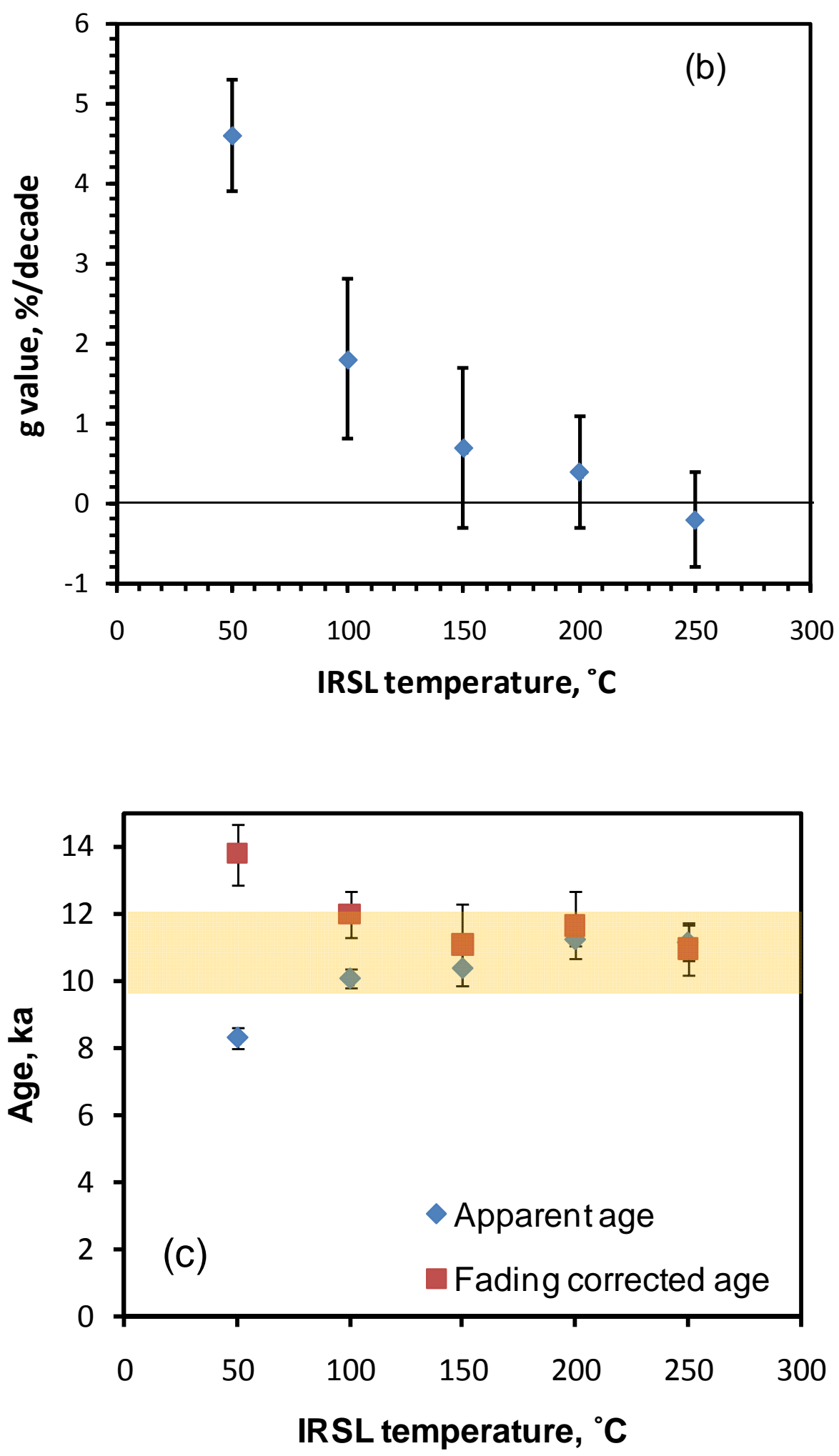

3 
Figure 6

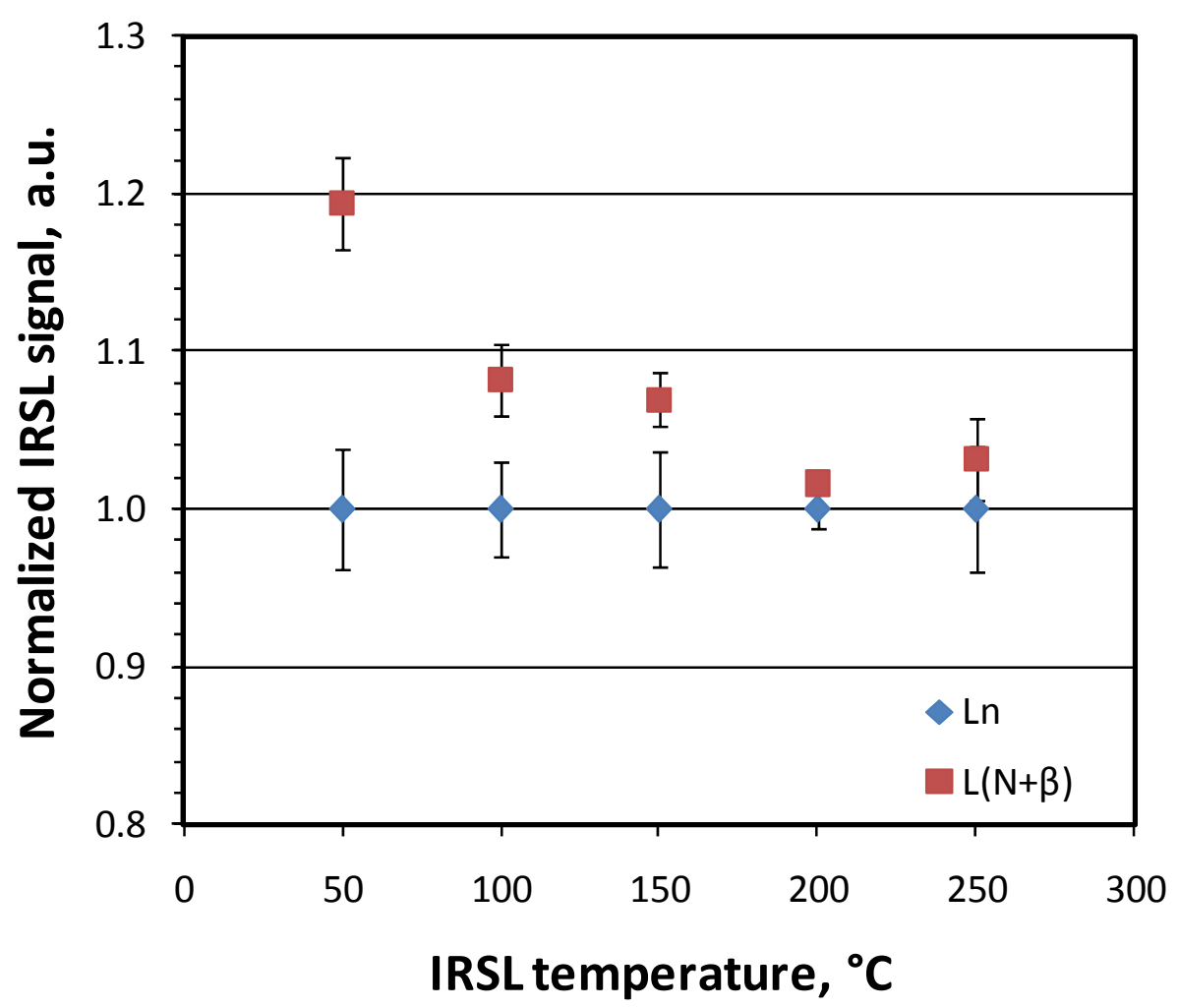

3 


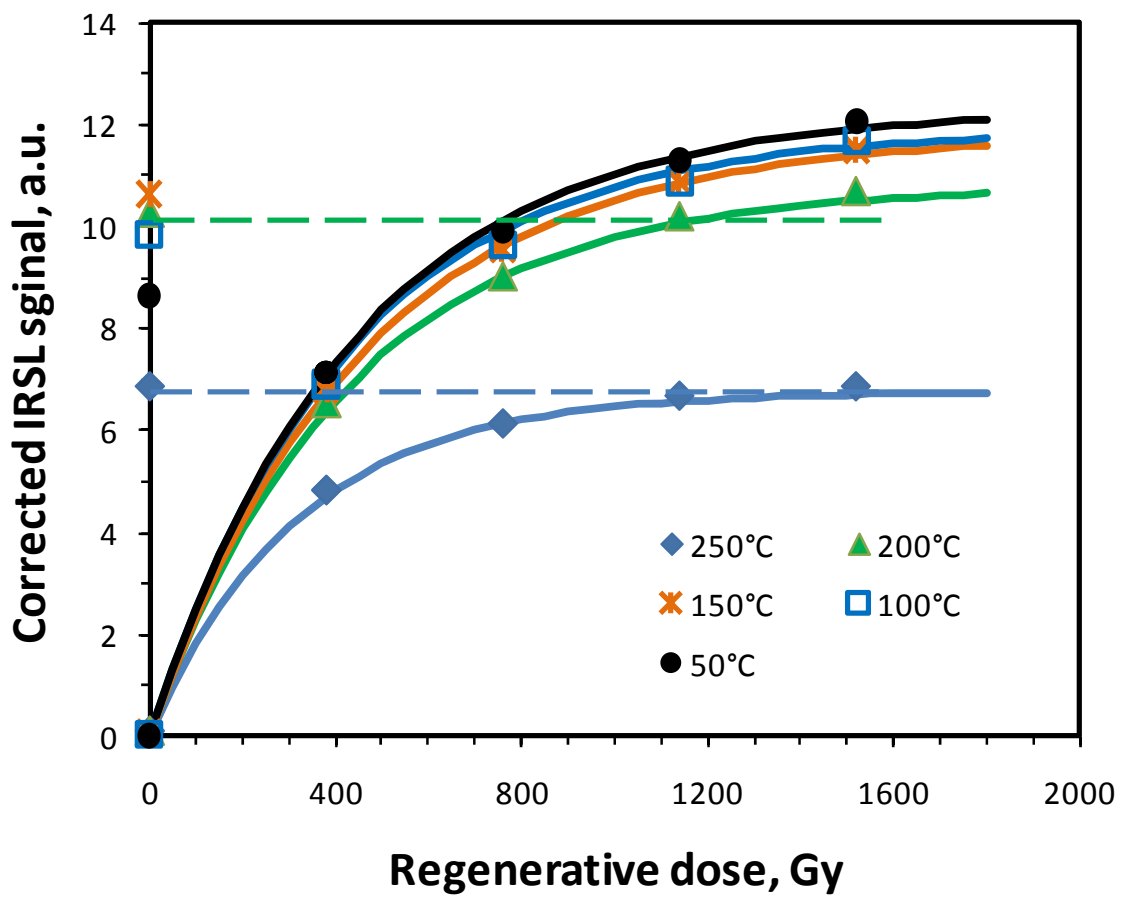

1

2

Figure 7

4

5

6 
2 Figure $8 \mathrm{a}$ and $8 \mathrm{~b}$
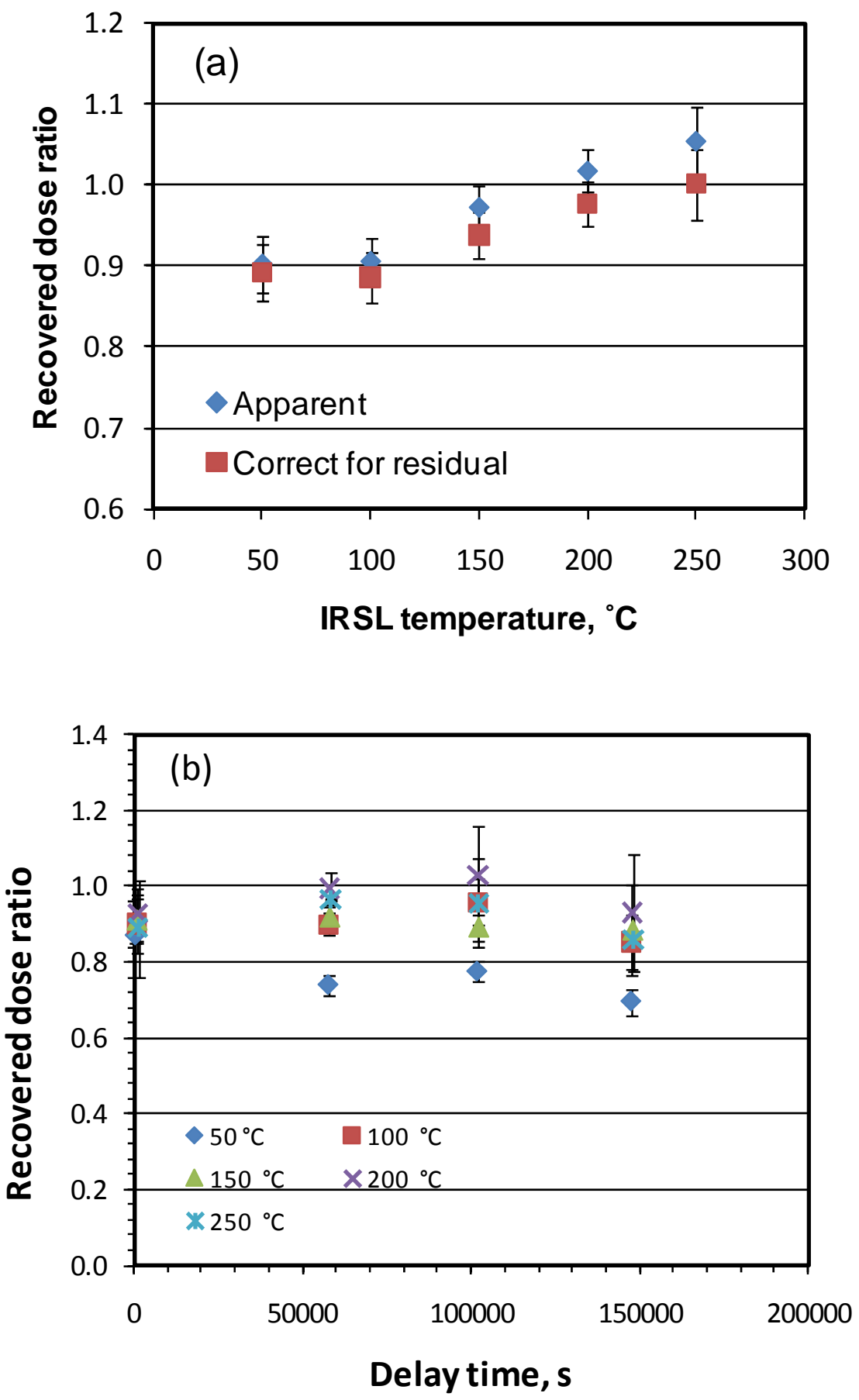

5

6 

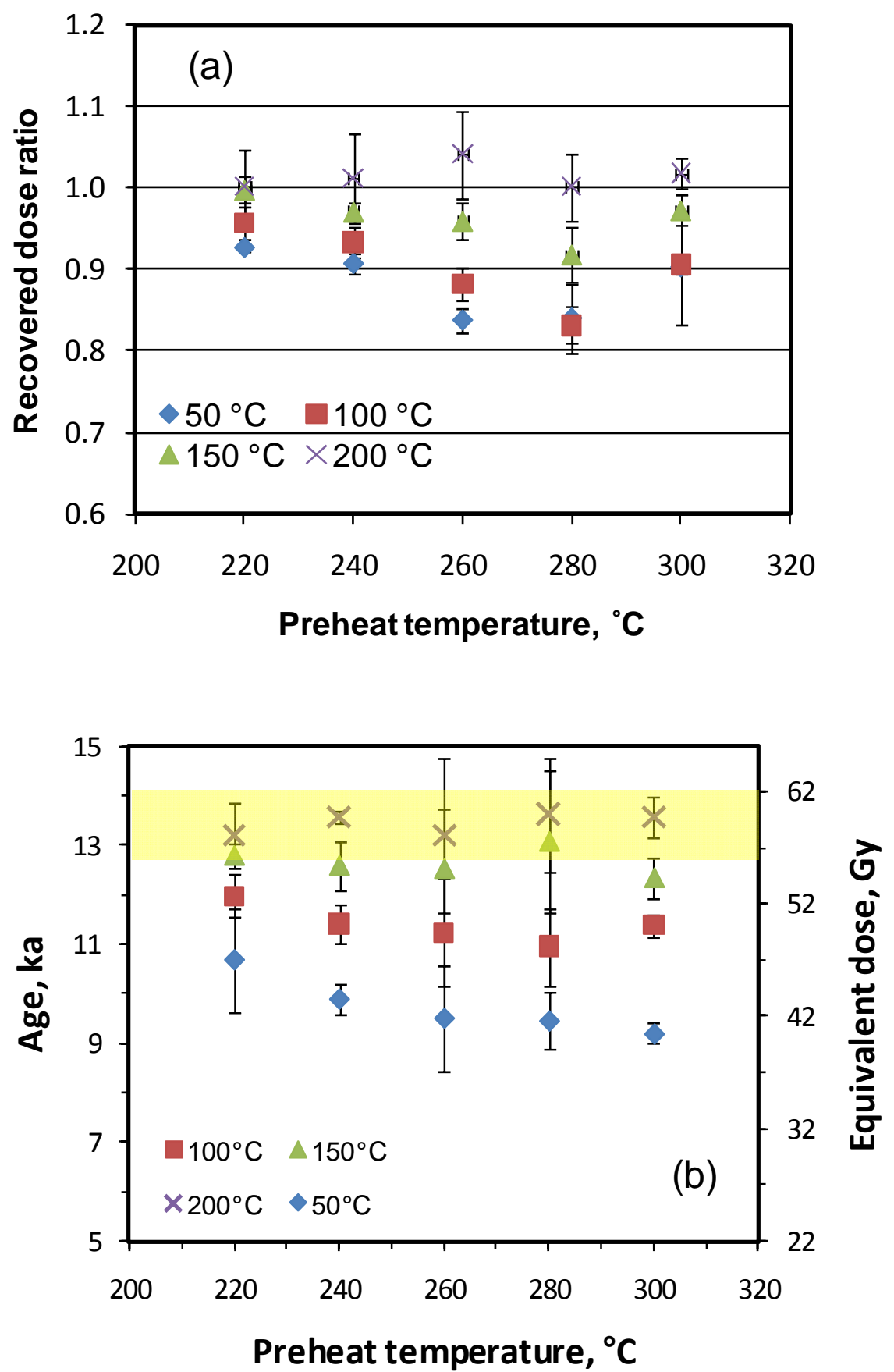

4 

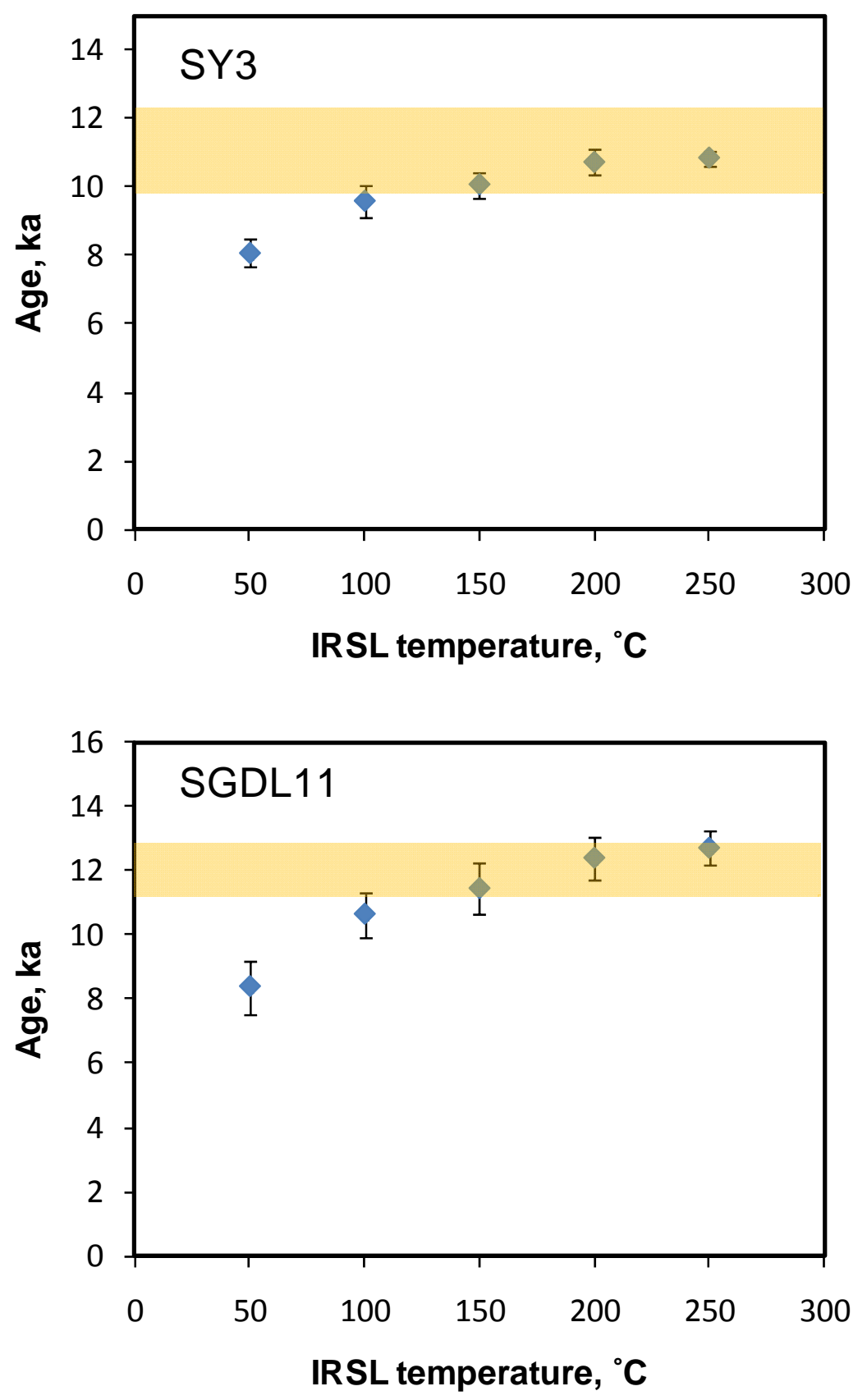

3

4 Figure 10a and $10 \mathrm{~b}$ 

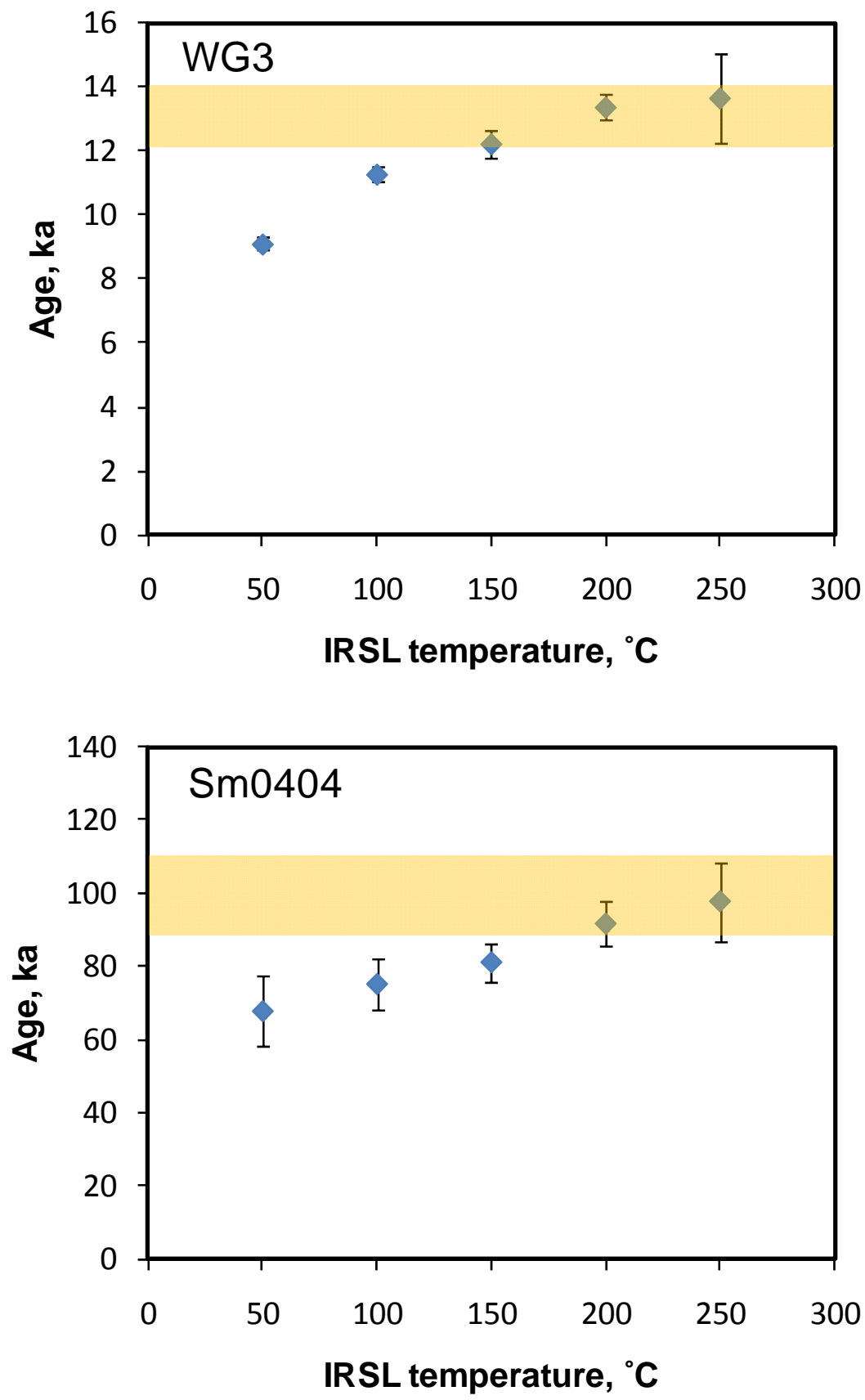

3

4

5

Figure 10c and 10d

6 

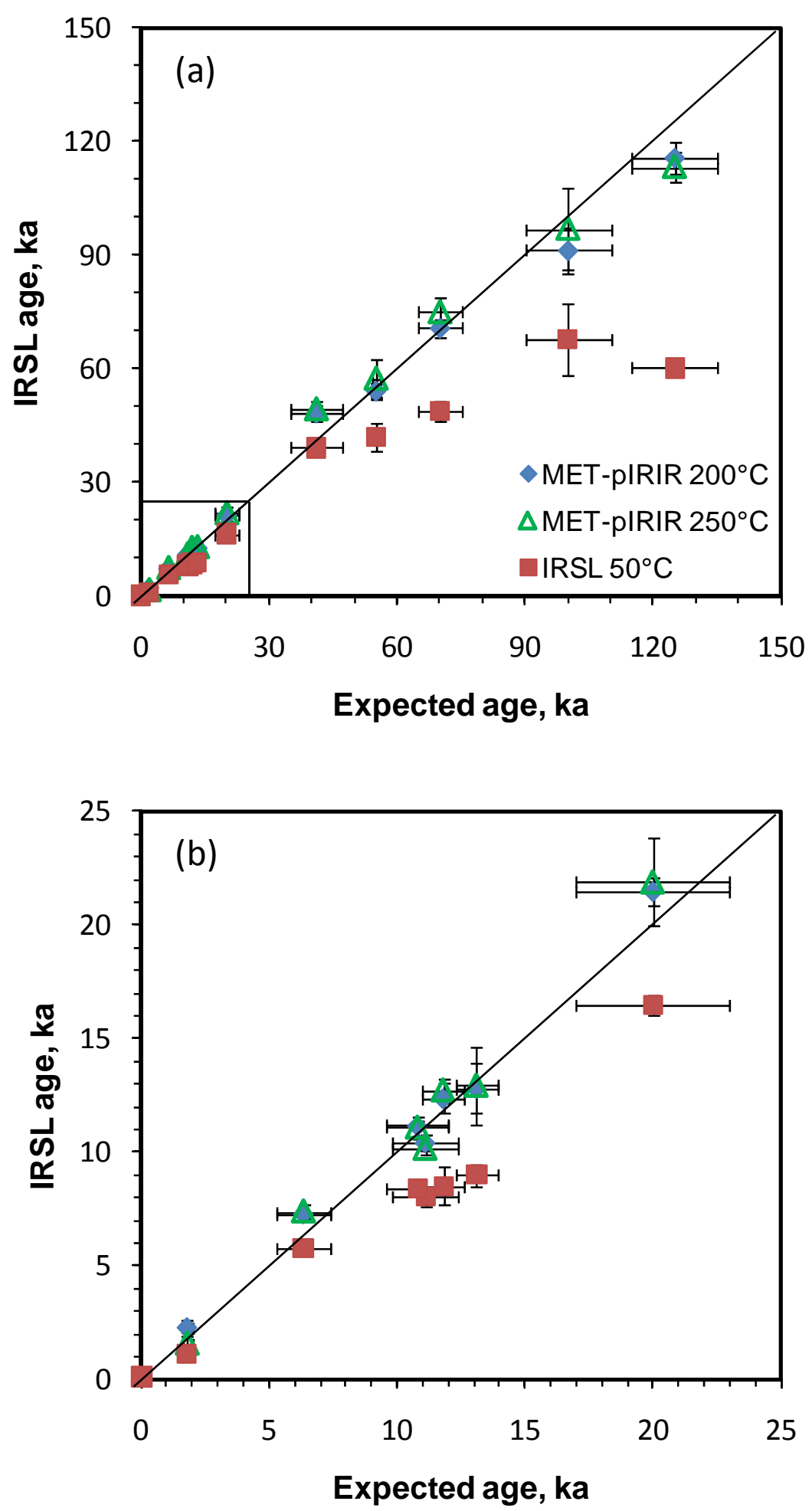


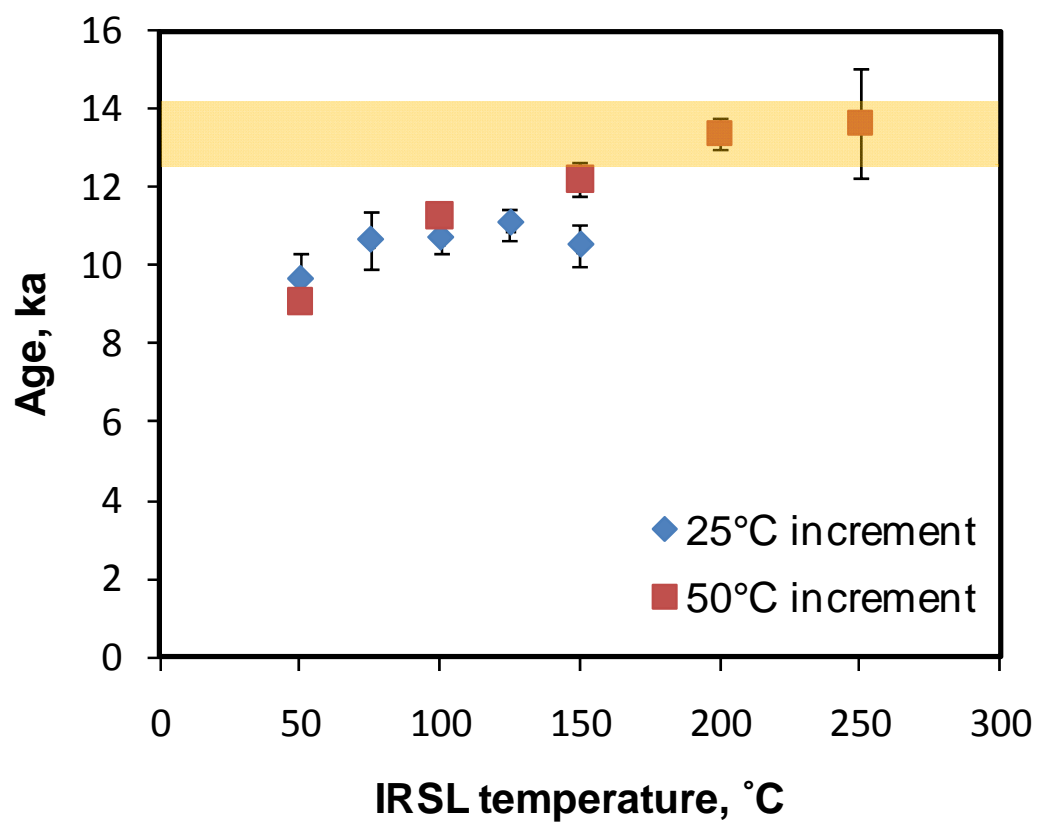

5

6 
Table 1: Summary of the dosimetry data for the samples

\begin{tabular}{|c|c|c|c|c|c|c|c|}
\hline Sample & $\begin{array}{c}\text { Grain size } \\
(\mu \mathrm{m})\end{array}$ & $\begin{array}{c}\text { K content } \\
(\%)\end{array}$ & $\begin{array}{c}\text { Alpha counting rate } \\
(\mathrm{cts} / \mathrm{ks})\end{array}$ & $\begin{array}{c}\text { Water content } \\
(\%)\end{array}$ & $\begin{array}{c}\text { Cosmic rays } \\
(\mathrm{Gy} / \mathrm{ka})\end{array}$ & $\begin{array}{c}\text { Ext. dose rate } \\
(\mathrm{Gy} / \mathrm{ka})\end{array}$ & $\begin{array}{c}\text { Int. dose rate }{ }^{\mathrm{a}} \\
(\mathrm{Gy} / \mathrm{ka})\end{array}$ \\
\hline SGDL-10 & $150-180$ & 2.32 & $3.92 \pm 0.13$ & 5 & 0.10 & $2.8 \pm 0.2$ & 0.72 \\
SGDL-11 & $180-212$ & 2.30 & $1.96 \pm 0.09$ & 4 & 0.09 & $2.5 \pm 0.1$ & 0.85 \\
SY3 & $180-212$ & 2.26 & $2.16 \pm 0.12$ & 4 & 0.21 & $3.0 \pm 0.1$ & 0.85 \\
HLD3 & $180-212$ & 2.39 & $4.14 \pm 0.16$ & 7 & 0.19 & $2.9 \pm 0.1$ & 0.85 \\
WG1 & $150-180$ & 2.65 & $5.48 \pm 0.18$ & 5 & 0.23 & $3.4 \pm 0.2$ & 0.72 \\
WG2 & $180-212$ & 2.48 & $4.03 \pm 0.16$ & 4 & 0.20 & $3.0 \pm 0.1$ & 0.85 \\
WG3 & $180-212$ & 2.56 & $7.62 \pm 0.21$ & 6 & 0.19 & $3.6 \pm 0.1$ & 0.85 \\
SM3 & $180-212$ & 2.32 & $4.97 \pm 0.13$ & 4 & 0.08 & $2.9 \pm 0.1$ & 0.85 \\
SM0404 & $150-180$ & 2.10 & $12.27 \pm 0.17$ & 7 & 0.05 & $3.6 \pm 0.1$ & 0.72 \\
SM5 & $150-180$ & 2.20 & $7.06 \pm 0.17$ & 4 & 0.03 & $3.0 \pm 0.1$ & 0.72 \\
LC-019 & $63-90$ & 1.70 & $11.68 \pm 0.20$ & 15 & 0.17 & $3.1 \pm 0.1$ & 0.36 \\
LC-093 & $63-90$ & 1.90 & $10.50 \pm 0.21$ & 20 & 0.06 & $2.9 \pm 0.1$ & 0.36 \\
FJGW1 & $150-180$ & 1.64 & $6.23 \pm 0.20$ & 7 & 0.01 & $2.3 \pm 0.1$ & 0.72 \\
\hline
\end{tabular}

2

3 Note: ${ }^{a}$ The internal dose rate for K-feldspar used in age calculation was estimated by assuming $\mathrm{K}=13 \pm 1 \%$ and $\mathrm{Rb}=400 \pm 100 \mathrm{ppm}(\mathrm{Li}$ et al. 2008 ;

4 Huntley and Baril, 1997; Zhao and Li, 2005; Huntley and Hancock, 2001). 
Table 2: The single-aliquot regenerative-dose (SAR) protocol for multi-elevated-temperatures post-IR IRSL.

\begin{tabular}{|c|c|c|}
\hline Step & Treatment & Observed \\
\hline 1 & Give regenerative dose, $D_{i}{ }^{a}$ & \\
\hline 2 & Preheat at $300^{\circ} \mathrm{C}$ for $10 \mathrm{~s}$ & \\
\hline 3 & IRSL measurement at $50^{\circ} \mathrm{C}$ for $100 \mathrm{~s}$ & $\mathbf{L}_{\mathbf{x}(50)}$ \\
\hline 4 & IRSL meausrement at $100^{\circ} \mathrm{C}$ for $100 \mathrm{~s}$ & $\mathbf{L}_{\mathbf{x}(\mathbf{1 0 0})}$ \\
\hline 5 & IRSL meausrement at $150^{\circ} \mathrm{C}$ for $100 \mathrm{~s}$ & $\mathbf{L}_{\mathrm{x}(150)}$ \\
\hline 6 & IRSL meausrement at $200^{\circ} \mathrm{C}$ for $100 \mathrm{~s}$ & $\mathbf{L}_{\mathbf{x}(200)}$ \\
\hline 7 & IRSL meausrement at $250^{\circ} \mathrm{C}$ for $100 \mathrm{~s}$ & $\mathbf{L}_{\mathrm{x}(250)}$ \\
\hline 8 & Give test dose, $D_{t}$ & \\
\hline 9 & Preheat at $300^{\circ} \mathrm{C}$ for $10 \mathrm{~s}$ & \\
\hline 10 & IRSL measurement at $50^{\circ} \mathrm{C}$ for $100 \mathrm{~s}$ & $\mathbf{T}_{\mathbf{x}(50)}$ \\
\hline 11 & IRSL meausrement at $100^{\circ} \mathrm{C}$ for $100 \mathrm{~s}$ & $\mathbf{T}_{\mathbf{x}(\mathbf{1 0 0})}$ \\
\hline 12 & IRSL meausrement at $150^{\circ} \mathrm{C}$ for $100 \mathrm{~s}$ & $\mathbf{T}_{\mathbf{x}(150)}$ \\
\hline 13 & IRSL meausrement at $200^{\circ} \mathrm{C}$ for $100 \mathrm{~s}$ & $\mathbf{T}_{\mathbf{x}(200)}$ \\
\hline 14 & IRSL meausrement at $250^{\circ} \mathrm{C}$ for $100 \mathrm{~s}$ & $\mathbf{T}_{\mathbf{x}(250)}$ \\
\hline 15 & IR bleaching at $320^{\circ} \mathrm{C}$ for $100 \mathrm{~s}$ & \\
\hline 16 & Return to step1 & \\
\hline
\end{tabular}

$2{ }^{\mathrm{a}}$ For the 'natural' sample, $\mathrm{i}=0$ and $\mathrm{D}_{0}=0$. The whole sequence is repeated for several regenerative doses including a zero dose and a repeat dose. 
1 Table 3: The measured doses and corresponding ages obtained using different signals and methods.

\begin{tabular}{|c|c|c|c|c|c|c|c|c|c|c|c|}
\hline \multirow[t]{2}{*}{ Sample } & \multirow[t]{2}{*}{ Expected age $^{\mathrm{a}}$, ka } & \multicolumn{5}{|c|}{ K-feldspar MET-pIRIR D , Gy } & \multicolumn{5}{|c|}{ K-feldspar MET-pIRIR ages ${ }^{\text {b }}$, ka } \\
\hline & & $50^{\circ} \mathrm{C}$ & $100^{\circ} \mathrm{C}$ & $150^{\circ} \mathrm{C}$ & $200^{\circ} \mathrm{C}$ & $250^{\circ} \mathrm{C}$ & $50^{\circ} \mathrm{C}$ & $100^{\circ} \mathrm{C}$ & $150^{\circ} \mathrm{C}$ & $200^{\circ} \mathrm{C}$ & $250^{\circ} \mathrm{C}$ \\
\hline SGDL10 & $6.3 \pm 1.1$ & $20.9 \pm 0.3$ & $24.8 \pm 1.2$ & $26.4 \pm 1.2$ & $27.4 \pm 0.2$ & $29.1 \pm 1.0$ & $5.7 \pm 0.1$ & $6.7 \pm 0.3$ & $7.2 \pm 0.3$ & $7.3 \pm 0.1$ & $7.4 \pm 0.3$ \\
\hline SGDL11 & $11.8 \pm 0.8$ & $29.3 \pm 2.8$ & $37.1 \pm 2.4$ & $39.9 \pm 2.7$ & $43.6 \pm 2.3$ & $46.2 \pm 1.8$ & $8.4 \pm 0.8$ & $10.6 \pm 0.7$ & $11.4 \pm 0.8$ & $12.4 \pm 0.7$ & $12.7 \pm 0.5$ \\
\hline SY3 & $11.1 \pm 1.3$ & $30.7 \pm 1.6$ & $36.5 \pm 1.7$ & $38.3 \pm 1.4$ & $40.7 \pm 1.4$ & $41.2 \pm 0.8$ & $8.0 \pm 0.4$ & $9.5 \pm 0.5$ & $9.9 \pm 0.4$ & $10.5 \pm 0.4$ & $10.2 \pm 0.2$ \\
\hline HLD3 & $10.8 \pm 1.2$ & $31.5 \pm 1.2$ & $38.2 \pm 1.1$ & $39.3 \pm 1.8$ & $43.0 \pm 0.6$ & $44.2 \pm 1.9$ & $8.3 \pm 0.3$ & $10.1 \pm 0.3$ & $10.4 \pm 0.5$ & $11.2 \pm 0.2$ & $11.1 \pm 0.5$ \\
\hline WG1 & $0.04 \pm 0.01$ & $0.5 \pm 0.1$ & $0.5 \pm 0.4$ & $0.5 \pm 0.1$ & $1.0 \pm 0.6$ & $2.4 \pm 1.2$ & $0.11 \pm 0.03$ & $0.12 \pm 0.10$ & $0.12 \pm 0.03$ & $0.23 \pm 0.14$ & $0.58 \pm 0.28$ \\
\hline WG2 & $1.8 \pm 0.2$ & $4.9 \pm 0.3$ & $6.9 \pm 0.7$ & $8.8 \pm 1.0$ & $10.2 \pm 1.4$ & $11.5 \pm 2.2$ & $1.1 \pm 0.1$ & $1.6 \pm 0.2$ & $2.1 \pm 0.3$ & $2.3 \pm 0.3$ & $2.3 \pm 0.6$ \\
\hline WG3 & $13.1 \pm 0.8$ & $40 \pm 1$ & $50 \pm 1$ & $54 \pm 2$ & $60 \pm 2$ & $62 \pm 6$ & $9.1 \pm 0.5$ & $11.3 \pm 0.7$ & $12.2 \pm 1.0$ & $13.4 \pm 1.1$ & $13.6 \pm 1.7$ \\
\hline SM3 & $41 \pm 6$ & $149 \pm 5$ & $159 \pm 13$ & $166 \pm 12$ & $185 \pm 8$ & $190 \pm 9$ & $39.1 \pm 1.2$ & $41.9 \pm 3.5$ & $43.6 \pm 3.3$ & $48.7 \pm 2.2$ & $50.0 \pm 2.3$ \\
\hline SM0404 & $100 \pm 10$ & $291 \pm 40$ & $323 \pm 29$ & $348 \pm 23$ & $394 \pm 26$ & $420 \pm 46$ & $67.7 \pm 9.6$ & $75.1 \pm 6.8$ & $81.0 \pm 5.4$ & $91.6 \pm 6.1$ & $97.7 \pm 10.7$ \\
\hline SM5 & $125 \pm 10$ & $253 \pm 9$ & $309 \pm 4$ & $347 \pm 3$ & $381 \pm 9$ & $407 \pm 19$ & $60.2 \pm 1.4$ & $74.3 \pm 4.1$ & $83.5 \pm 4.6$ & $116.0 \pm 4.0$ & $114.0 \pm 4.0$ \\
\hline FJGW1 & $55.7 \pm 1.0$ & $121 \pm 11$ & $133 \pm 6$ & $143 \pm 6$ & $158 \pm 6$ & $168 \pm 15$ & $41.9 \pm 3.6$ & $45.9 \pm 2.1$ & $49.4 \pm 2.2$ & $54.5 \pm 1.9$ & $58.1 \pm 5.3$ \\
\hline LC-019 & $20 \pm 3$ & $54 \pm 1$ & $64 \pm 1$ & $67 \pm 2$ & $72 \pm 2$ & $75 \pm 6$ & $16.3 \pm 0.4$ & $19.2 \pm 0.4$ & $20.0 \pm 0.5$ & $21.5 \pm 0.6$ & $21.8 \pm 1.9$ \\
\hline LC-093 & $70 \pm 5$ & $153 \pm 9$ & $199 \pm 5$ & $208 \pm 11$ & $223 \pm 7$ & $237 \pm 13$ & $48.7 \pm 2.8$ & $63.4 \pm 1.5$ & $66.0 \pm 3.4$ & $70.8 \pm 2.3$ & $74.8 \pm 4.2$ \\
\hline
\end{tabular}

2 Note: ${ }^{a}$ The expected ages of sample Sm0404 and Sm5 shown in the table are based on stratigraphic correlation (Sun et al., 1999). For other samples, all ages

3 shown in this column are based on quartz OSL ages.

$4{ }^{\mathrm{b}}$ The MET-pIRIR ages for young samples, SGDL-10, SGDL-11, WG2, WG3, HLD3, LC-019 and SY3 are corrected for residual doses obtained from the

5 mordern sand sample WG1. For other older samples, no correction was made since this resulted in negligible effect. 